\title{
Annulus eccentricity optimisation of a phase-change material (PCM) horizontal double-pipe thermal energy store
}

\author{
M.R. Kadivar ${ }^{a}$, M.A. Moghimi ${ }^{b}$, , P. Sapin ${ }^{c}$, C.N. Markides ${ }^{c}$ \\ ${ }^{a}$ Centre for Precision Engineering, Material \& Manufacturing Research (PEM Centre), Department of Mechanical and Manufacturing Engineering, Institute of Technology Sligo, Sligo, Ireland \\ ${ }^{\mathrm{b}}$ Department of Design and Engineering, Staffordshire University, Stoke-On-Trent ST4 2DE, United Kingdom \\ ${ }^{\mathrm{c}}$ Clean Energy Processes (CEP) Laboratory, Department of Chemical Engineering, Imperial College London, London, United Kingdom
}

\section{A R T I C L E I N F O}

\section{Keywords}

CFD

Phase change material

Thermal energy storage

Optimization

Charging

Discharging

Eccentric

\begin{abstract}
A B S T R A C T
The application of phase-change materials (PCMs) has received significant interest for use in thermal energy storage (TES) systems that can adjust the mismatch between the energy availability and demand. In the building sector, for example, PCMs can be used to reduce air-conditioning energy consumption by increasing the thermal capacity of the walls. However, as promising this technology may be, the poor thermal conductivity of PCMs has acted as a barrier to its commercialization, with many heat-transfer enhancement solutions proposed in the literature, such as microencapsulation or metal foam inserts, being either too costly and/or complex. The present study focuses on a low-cost and highly practical solution, in which natural-convective heat transfer is enhanced by placing the PCM in an eccentric annulus within a horizontal double-pipe TES heat exchanger. This paper presents an annulus-eccentricity optimisation study, whereby the optimal radial and tangential eccentricities are determined to minimize the charging time of a PCM thermal energy store. The storage performance of several geometrical configurations is predicted using a computational fluid dynamics (CFD) model based on the enthalpy-porosity formulation. The optimal geometrical configuration is then determined with response surface methods. The horizontal double-pipe heat exchanger studied considered here is an annulus filled with N-eicosane as the PCM for initial studies. In presence of N-eicosane, for the concentric configuration (which is the baseline case), the charging is completed at $F o=0.64$, while the charging of optimum eccentric geometries with the quickest and slowest charging is completed at $F_{O}=0.09$ and $F_{O}=2.31$, respectively. In addition, an investigation on the discharging performance of the studied configurations with N-eicosane shows the quickest discharge occurs with the concentric annulus case at $F_{O}=0.99$, while the discharge time of the proposed optimum annuli is about three times this value. In other words, the proposed optimum geometry with the quickest charging time charges $\sim 7.1$ times faster but also discharges $\sim 3$ times slower, which is ideal for a TES, especially when used as passive thermal storage systems in nearly zero-emission buildings. Complementary studies demonstrate that the proposed optimum configuration improves the TES performance also when employing other PCM types as well as various shell-to-tube diameter ratios.
\end{abstract}

\begin{tabular}{|ll|}
\hline \multicolumn{2}{|l|}{ Nomenclature } \\
$A$ & Mushy zone constant $\left(\mathrm{kg} / \mathrm{m}^{3} \mathrm{~s}\right)$ \\
$C^{*}$ & Dimensionless Darcy coefficient, $\frac{(1-f)^{2} A_{\text {mush }} D^{2}}{\left(f^{3}-\varepsilon\right) \rho}$ \\
$c_{\mathrm{p}}$ & Specific heat $(\mathrm{J} / \mathrm{kg} \mathrm{K})$ \\
$D$ & Hydraulic diameter $(\mathrm{m})$ \\
$f$ & Liquid fraction \\
Fo & Fourier number, $\frac{\alpha t}{D^{2}}$ \\
$\mathrm{~g}$ & Gravitational acceleration constant $\left(\mathrm{m} / \mathrm{s}^{2}\right)$ \\
$h$ & Sensible enthalpy $(\mathrm{J} / \mathrm{kg})$ \\
$H$ & Total enthalpy $(\mathrm{J} / \mathrm{kg})$ \\
\hline
\end{tabular}

\begin{tabular}{|ll|}
\hline$H^{*}$ & Non-dimensional enthalpy, $\frac{H}{c_{\mathrm{p}}\left(T_{\mathrm{s}}-T_{\mathrm{i}}\right)}$ \\
$k$ & Thermal conductivity $(\mathrm{W} / \mathrm{m} \mathrm{K})$ \\
$L$ & Latent heat $(\mathrm{J} / \mathrm{kg})$ \\
$m$ & Mass $(\mathrm{kg})$ \\
$P$ & Pressure (Pa) \\
$P^{*}$ & Non-dimensional pressure, $\frac{P}{D^{2} / \rho \alpha^{2}}$ \\
$P r$ & Prandtl number, $\frac{v}{\alpha}$ \\
$Q$ & Heat, thermal energy $(\mathrm{J})$ \\
$R$ & Radius (m) \\
$R a$ & Rayleigh number, $\frac{g \beta \Delta T D^{3}}{\alpha \nu}$ \\
$r$ & Radial eccentricity $(\mathrm{m})$ \\
\hline
\end{tabular}

\footnotetext{
* Corresponding author.

E-mail address: moghimi64@gmail.com (M.A. Moghimi)
} 


\begin{tabular}{|ll|}
\hline$r^{*}$ & Non-dimensional radial eccentricity, $\frac{r}{D / 2}$ \\
$S$ & Source term $\mathrm{kg} / \mathrm{m}^{2} \mathrm{~s}^{2}$ \\
Ste & Stefan number, $\frac{c_{\mathrm{p}}\left(T_{\mathrm{s}}-T_{\mathrm{i}}\right)}{L}$ \\
$t$ & Time (s) \\
$T$ & Temperature $(\mathrm{K})$ \\
$T^{*}$ & Non-dimensional temperature, $\frac{T-T_{\mathrm{i}}}{T_{\mathrm{s}}-T_{\mathrm{i}}}$ \\
$v$ & Velocity (m/s) \\
$v^{*}$ & Non-dimensional velocity, $\frac{v D}{\alpha}$ \\
$\rho$ & Density $\left(\mathrm{kg} / \mathrm{m}^{3}\right)$ \\
$\rho^{*}$ & Non-dimensional density, $\frac{\rho}{\rho_{0}}$ \\
$\alpha$ & Thermal diffusivity (m $\left.{ }^{2} / \mathrm{s}\right)$ \\
$\mu$ & Dynamic viscosity (Pa s) \\
$\varepsilon$ & Small number \\
$\theta$ & Tangential eccentricity (rad) \\
$\eta$ & Storage rate \\
$\beta$ & Volumetric expansion coefficient $(1 / \mathrm{K})$ \\
1 & Liquid \\
$\mathrm{i}$ & Initial \\
in & Inner \\
$\mathrm{m}$ & Melting \\
mush & Mushy zone \\
out & Outer \\
ref & Reference \\
$\mathrm{s}$ & Surface \\
$\mathrm{se}$ & Sensible \\
$\mathrm{t}$ & Total \\
$\mathrm{CFD}$ & Computational fluid dynamics \\
$\mathrm{DOE}$ & Design of experiments \\
$\mathrm{DPHX}$ & Double-pipe heat exchanger \\
$\mathrm{HTF}$ & Heat-transfer fluid \\
$\mathrm{NLPQL}$ & Non-linear programming by quadratic Lagrangian \\
$\mathrm{PCM}$ & Phase change material \\
$\mathrm{SDHW}$ & Solar domestic hot water \\
$\mathrm{TES}$ & Thermal energy storage \\
& \\
\hline & \\
\hline
\end{tabular}

\section{Introduction}

Thermal energy storage (TES) applies for accommodating the needs in thermal energy when the supply and demand are inequitable [1-3]. Application of phase-change materials (PCMs) in TES systems has gained significant attention since they have minimal energy loss and high storage density [3-5] (PCM storage density is 5 to 10 times higher than that of sensible heat storage materials such as water $[6,7]$ ). PCMs can be classified into three categories, depending on the experienced phase change, namely: solid-solid, liquid-gas, and solid-liquid. Relatively few solid-solid PCMs have been recognized for thermal storage applications. Although liquid-gas PCMs usually exhibit high heats of transformation, the large density ratio between the two phases makes them rather impractical for thermal storage $[6,8]$. Solid-liquid PCMs take advantage of considerable high storage density with a marginal change in temperature and volume $[6,8]$. The energy stored as latent heat of fusion during the melting of the PCM (referred to as the charging process) is later recovered during the solidification process (referred to as the discharging process). However, the poor thermal conductivity of solid-liquid PCMs, which limits the heat flow rate, has hindered their widespread application $[9,10]$.

Passive and active heat transfer enhancement approaches can compensate for poor thermophysical properties of materials used in heat exchangers [11-14]. Several heat-transfer enhancement techniques proposed over the past three decades to overcome this deficiency in TES have been reviewed by Jegadheeswaran and Pohekar [5]. Most of the suggested improvements, which include extended surfaces $[15,16$
], PCM micro-encapsulation $[17,18]$, impregnation of porous material with PCM $[19,20]$, dispersion of high conductivity particles in the PCM [21-24], metal foam inserts [25,26], and high-conductivity and low-density materials $[15,27]$ - are costly and sometimes impractical in large-scale TESs. Panchabikesan et al. [28] investigated the effect of PCM thermal conductivities on the performance of a TES unit. They reported that increasing PCM thermal conductivity from 0.2 to $0.6 \mathrm{~W} / \mathrm{m} . \mathrm{K}$ significantly reduces the charging time. However, the effect of PCM thermal conductivity beyond $0.8 \mathrm{~W} / \mathrm{m} . \mathrm{K}$ is negligible. Kalapala and Devanuri [29] reviewed the influence of different design parameters on the performance of TES systems. They reported that apart from PCM thermophysical properties, operating and geometric parameters have a significant impact on the charging and discharging time of TES units. However, a number of studies consider simple, economic and practical approaches for enhancing heat transfer in PCMs, by focusing on the influence of the geometry, inclination, and shape of the heat exchanger. In the following, these simple solutions are reviewed and discussed.

Khillarkar et al. [30] performed a finite-element numerical study of PCM melting in concentric horizontal annuli with two different configurations: a circular tube inside a square (Type A) and a square inside a circular tube (Type B). A numerical study was carried out for each of the arrangements with heating at the inside, outside or both walls. The faster rate of melting is observed as a result of better mixing between the melting zones formed by heating both the inner and outer walls. Zivkovic and Fuji [31] and later Vyshak and Jilani [32] employed enthalpy methods in order to study the melting process of calcium chloride hexahydrate packed in three containers with different configurations: rectangular, cylindrical and double-pipe heat exchangers. The results indicate that: (i) the charging time in the cylindrical container is twice longer than that in the rectangular container, and (ii) the cylindrical double-pipe exchangers favourably decrease the melting time compared to former configurations for similar volume and heat-transfer area. These studies proved the cylindrical double-pipe heat exchanger (DPHX) to be one of the most efficient geometries for TES applications.

The influence of the inclination on the performance of TES systems using DPHXs has been further investigated both numerically and experimentally [33-38]. Murray et al. [33] experimentally compared the consecutive charging and discharging performance of a vertical TES unit. It was found that, despite the presence of a large amount of the molten PCM at the top of the container, negligible effect on the solidification process was observed. Seddegh et al. [34] numerically investigated the thermal behaviour of a vertical cylindrical DPHX by comparing pure thermal conduction and combined conduction-convection heat-transfer models. It was found that the combined model offers better predictions of the heat transfer in the PCM than the pure conduction model. The analyses demonstrated that natural convection plays a significant role during the charging process, while it has negligible influence in the discharging process.

Seddegh et al. [35] experimentally recorded the effect of different inner-tube radii on the thermal behaviour of a vertical cylindrical double-pipe TES system. They observed that the complete charge and discharge depend on the shell-to-tube (i.e., outer-to-inner) radius ratio. The same authors [36] further investigated the characteristics of the natural convective heat transfer in the same storage system. They observed that a narrowed vertical liquid PCM layer was initially formed around the heat-transfer fluid (HTF) pipe during melting. Buoyancy force drives natural convection in the radial direction, which further enhances the heat transfer in the upper part of the storage unit. Observations also showed that the solidification progressed in both radial and axial direction, simultaneously. Kousha et al. [37] evaluated experimentally the influence of the inclination angle on the performance of a double-pipe heat-storage system. It was found that the variation of the inclination angle does not influence the heat transfer during 
solidification, while the heat flow rates achieved during melting were higher in horizontal than in vertical storage systems. These findings were also confirmed by an independent study conducted by Seddegh et al. [38], where the thermal characteristics of horizontal and vertical double-pipe TES units were compared.

According to the above findings, horizontal double-pipe heat exchangers exhibit a better performance in TES systems, which is the reason why more interest has been shown for this configuration [39-42]. Hosseini et al. [39] performed experimental and computational investigations of the heat transfer in horizontal double-pipe systems using paraffin (RT50) as the PCM. They demonstrated that, although the heat transfer in PCMs is a convection-diffusion problem, the overall heat transfer is governed by the buoyancy-driven recirculations. Rösler and Brüggemann [40] conducted numerical and experimental studies of convection dominated melting processes inside a horizontal double-pipe TES unit. They implemented the enthalpy-porosity method by a continuous liquid fraction function into the open-source CFD framework OpenFOAM. The results showed that, while the natural convection influences the whole upper part of the TES, the lower part of the storage unit is dominated by conductive heat transfer. Avic and Yazici [41] recorded experimental results regarding the melting and solidification characteristics of paraffin (P56-58). It was found that the molten PCM ascends radially upwards to the upper part of the storage unit due to natural convection, resulting in radially asymmetric temperature fields. Unlike the charging process, the solidification was found to be initially dominated by natural convection and then by heat diffusion. Wang et al. [42] developed a numerical model to predict the transient behaviour of a horizontal double-pipe storage unit. The results demonstrate that the charging and discharging processes both occur in three distinctive phases, which are: (i) a buoyancy-driven highly dynamic, fast phase-change rate period, (ii) a slow transient period governed both by heat diffusion and convection, and (iii) a period dominated by heat conduction. It was also observed that in similar conditions, the discharging process reaches steady-state conditions more rapidly than the charging process.

As discussed above, the horizontal DPHX is considered by many as the simplest and most practical designs for PCM-based thermal stores. However, it is also acknowledged that the storage performance of these units can be further improved with slight modifications in the design. Several studies are notably dedicated to the influence of the inner-pipe eccentricity on the charging/discharging times [43-49], that are discussed below.

Zhang and Faghri [43] numerically and analytically investigated the sonification process in an eccentric horizontal annulus. They proved that the radial eccentricity declines the solidification rate. Dutta et al. [44] and Dhaidan et al. [45] experimentally and numerically studied the melting process in an eccentric horizontal double-pipe TES. They found that both radial and tangential eccentricity plays an important role in the net circulation of the molten PCM. Darzi et al. [46] studied numerically the melting of N-eicosane as PCM in horizontal concentric and eccentric annuli. They indicated that a faster melting occurred in the upper part of the inner cylinder. Moreover, when the inner cylinder is shifted to the lowermost part of the outer cylinder, the melting rate soars due to an extended region influenced by natural convection. Yazici et al. $[47,48]$ experimentally investigated the effect of radial eccentricity on the solidification and melting of paraffin in a horizontal double-pipe storage system. They demonstrated that regardless of the specific position of inner tube related to the centre (moving the inner tube along the $y$-axis in the positive and negative direction), eccentricity would generally increase the time needed for complete solidification. Nonetheless, increasing radial eccentricity toward the lowermost part of the sell drastically decreases melting time. Pahamli et al. [49] applied a computational model to study the eccentricity and operational parameters in a horizontal double-pipe TES unit. It was found that by moving the inner cylinder down from its centre (radial eccentricity along the negative $y$-axis), the natural convection covers more area of PCM which drastically reduces the melting time.

More recently, in a closely related study of particular interest, Zheng et al. [50] investigated the performance of a double-pipe TES filled with n-octadecane by examining the role of the radial eccentricity of the proposed geometry. This work considered various geometric configurations with different radial eccentricities through a series of simulations (as case studies), which have provided us with valuable insight on the performance of these TES geometries. Based on their findings from the case studies, the authors discussed the optimum eccentricity and reported that, although an increase in the radial eccentricity from the centre of the shell downwards reduces the total melting time, this higher eccentricity does not always guarantee a better melting performance. Although an optimum eccentricity is proposed by Zheng et al. [50], they acknowledge in the conclusions that this may not be globally optimal due to the melting performance of the TES. This conclusion concerning the proposed result not being a formal optimum solution is expected due the selected methodology in that work, which does not focus on implementing formal optimization techniques in predicting an optimal geometry. However, Zheng et al. [50] work is based on the comparison of a series of carefully-performed CFD simulations of a number of discrete cases with different radial eccentricities to choose a best geometrical solution (eccentricity). In that work the researchers only considered one PCM type and a single shell-to-tube diameter throughout their study. Motivated by this earlier work, the present study extends the research focus by employing a formal, response-surface-based optimization method to simultaneously optimize the radial and tangential eccentricities of the proposed geometry, while also attempting to generalize the results of the optimization study by considering the influence of various PCMs and shell-to-tube diameter ratios.

According to the aforementioned discussion (as summarised in Table 1), it is concluded that the eccentric horizontal double-pipe heat exchanger is the simplest, most economic and practical approach to enhance the performance of such TES units. Hence, this study focuses on the optimisation of the eccentricity of a double-pipe TES system, to offer the best configuration for TES units, to which no attention has been paid so far, to the best of authors' knowledge. To perform this optimisation, the present study uses response-surface optimisation methods together with CFD simulations to determine the utopian geometries that lead to the quickest and slowest charging times. Later, this study investigates the discharging behaviour of the proposed geometries. The detailed explanations of the model, methods, and results are presented and discussed in the following sections.

\section{Computational methods}

\subsection{TES design}

The charging and discharging of a PCM placed within a horizontal double-pipe heat exchanger acting as a TES device involves complex thermofluid processes that are solved in the present study using computational fluid dynamics (CFD) tools. The configuration investigated herein (see Fig. 1) is a horizontally-oriented eccentric annulus placed within an outer cylinder filled with a phase-change material. The objective is to find utopian combinations of both the radial $(r)$ and tangential $(\theta)$ eccentricities to induce the quickest and slowest charging processes (melting of the PCM). The independent variables $r$ and $\theta$ were defined as the radial distance of the centre of the inner cylinder $\left(c_{i}\right)$ from the centre of the outer cylinder $\left(c_{0}\right)$ and the angle between the negative $y$-axis and the $c_{0}-c_{\mathrm{i}}$ axis, as shown in Fig. 1 . The outer tube was assumed adiabatic (perfectly insulated) and the inner tube was assumed to be at a constant temperature. 
Table 1

Overview of literature relating to PCMs for TES applications.

\begin{tabular}{|c|c|c|c|c|c|c|c|c|}
\hline Ref. & Study type & & Process & & PCM & Orientation & $\begin{array}{l}\text { Approach for } \\
\text { charging } \\
\text { improvement }\end{array}$ & Findings and conclusions \\
\hline & Numerical & Experimental & Charging & Discharging & & & & \\
\hline$[30]$ & $\checkmark$ & & $\checkmark$ & & $\begin{array}{l}\mathrm{N}- \\
\text { Octadecane }\end{array}$ & Horizontal & $\begin{array}{l}\text { Heating both } \\
\text { inner and outer } \\
\text { wall }\end{array}$ & $\begin{array}{l}\text { The faster rate of melting due to better mixing. } \\
\text { Require more flow rate which also increases flow } \\
\text { losses in both PCM and HTF. }\end{array}$ \\
\hline [31] & $\checkmark$ & & $\checkmark$ & & $\begin{array}{l}\text { Calcium } \\
\text { Chloride } \\
\text { Hexahydrate }\end{array}$ & Horizontal & $\begin{array}{l}\text { Using a } \\
\text { rectangular } \\
\text { container instead } \\
\text { of a cylindrical } \\
\text { one }\end{array}$ & Rectangular container increases flow losses. \\
\hline [32] & $\checkmark$ & & $\checkmark$ & & $\begin{array}{l}\text { Calcium } \\
\text { Chloride } \\
\text { Hexahydrate }\end{array}$ & Horizontal & $\begin{array}{l}\text { Using a double } \\
\text { pipe as PCM } \\
\text { container }\end{array}$ & $\begin{array}{l}\text { The double-pipe heat exchanger is one of the most } \\
\text { favourable configurations in TES applications }\end{array}$ \\
\hline [33] & & $\checkmark$ & $\checkmark$ & $\checkmark$ & $\begin{array}{l}\text { Dodecanoic } \\
\text { Acid }\end{array}$ & Vertical & $\begin{array}{l}\text { Consecutive } \\
\text { charging and } \\
\text { discharging }\end{array}$ & $\begin{array}{l}\text { Modification of geometrical design parameters can } \\
\text { maximize the rate of energy storage by augmentation } \\
\text { of natural convection heat transfer. }\end{array}$ \\
\hline [34] & $\checkmark$ & & $\checkmark$ & $\checkmark$ & $\begin{array}{l}\text { Paraffin } \\
\text { Wax }\end{array}$ & Vertical & & $\begin{array}{l}\text { Natural convection plays a significant role during the } \\
\text { charging process, while it has negligible influence in } \\
\text { the discharging process. }\end{array}$ \\
\hline [35] & & $\checkmark$ & $\checkmark$ & $\checkmark$ & $\begin{array}{l}\text { Paraffin } \\
\text { RT60 }\end{array}$ & Vertical & $\begin{array}{l}\text { Increasing shell- } \\
\text { to-tube radius } \\
\text { ratio }\end{array}$ & $\begin{array}{l}\text { Increasing the shell-to-tube ratio restricted to a specific } \\
\text { ratio }\end{array}$ \\
\hline$[36]$ & $\checkmark$ & $\checkmark$ & $\checkmark$ & $\checkmark$ & $\begin{array}{l}\text { Paraffin } \\
\text { RT60 }\end{array}$ & Vertical & & $\begin{array}{l}\text { Melting growth mostly at the upper part in the radial } \\
\text { direction while solidification progressed in both radial } \\
\text { and axial direction, simultaneously. }\end{array}$ \\
\hline [37] & $\checkmark$ & $\checkmark$ & $\checkmark$ & $\checkmark$ & $\begin{array}{l}\text { Paraffin } \\
\text { RT35 }\end{array}$ & $\begin{array}{l}\text { Inclined } \\
\text { (from } \\
\text { horizontal } \\
\text { to vertical } \\
\text { cases) }\end{array}$ & $\begin{array}{l}\text { Inclined double } \\
\text { pipe }\end{array}$ & $\begin{array}{l}\text { Horizontal double pipe heat exchanger outperforms } \\
\text { that of vertical one during the charging process. } \\
\text { Inclination does not effect on discharging process. }\end{array}$ \\
\hline [38] & $\checkmark$ & & $\checkmark$ & $\checkmark$ & $\begin{array}{l}\text { Paraffin } \\
\text { RT50 }\end{array}$ & $\begin{array}{l}\text { Horizontal } \\
\text { \& Vertical }\end{array}$ & $\begin{array}{l}\text { Using horizontal } \\
\text { shell-and-tube } \\
\text { instead of } \\
\text { vertical one }\end{array}$ & $\begin{array}{l}\text { Horizontal shell-and-tube offers better heat transfer } \\
\text { performance during the charging process }\end{array}$ \\
\hline [39] & $\checkmark$ & $\checkmark$ & $\checkmark$ & $\checkmark$ & $\begin{array}{l}\text { Paraffin } \\
\text { RT50 }\end{array}$ & Horizontal & & $\begin{array}{l}\text { Recirculation driven by convection governs the overall } \\
\text { heat transfer in the melting process. }\end{array}$ \\
\hline [40] & $\checkmark$ & $\checkmark$ & $\checkmark$ & & Gallium & Horizontal & & $\begin{array}{l}\text { The whole upper part of the TES influenced by the } \\
\text { natural convection, while lower part dominated by } \\
\text { conduction heat transfer. }\end{array}$ \\
\hline [41] & & $\checkmark$ & $\checkmark$ & $\checkmark$ & $\begin{array}{l}\text { Paraffin } \\
\text { P56-58 }\end{array}$ & Horizontal & & $\begin{array}{l}\text { Natural convection results in radially asymmetric } \\
\text { temperature field at the upper part of the storage unit. }\end{array}$ \\
\hline [42] & $\checkmark$ & & $\checkmark$ & $\checkmark$ & $\begin{array}{l}\mathrm{N}- \\
\text { Octadecane }\end{array}$ & Horizontal & & $\begin{array}{l}\text { The charging and discharging processes have three } \\
\text { distinctive phases: rapidly changing period, transient } \\
\text { slowly changing period and more slowly changing } \\
\text { period. }\end{array}$ \\
\hline [43] & $\checkmark$ & & & & 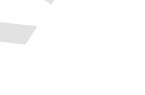 & Horizontal & $\begin{array}{l}\text { Using eccentric } \\
\text { double pipe heat } \\
\text { exchanger. }\end{array}$ & $\begin{array}{l}\text { Increasing the radial eccentricity reduces the } \\
\text { solidification rate. }\end{array}$ \\
\hline [44] & $\checkmark$ & $\checkmark$ & $\checkmark$ & & $\begin{array}{l}\text { Paraffin } \\
\text { Wax }\end{array}$ & Horizontal & $\begin{array}{l}\text { Using eccentric } \\
\text { double pipe heat } \\
\text { exchanger. }\end{array}$ & $\begin{array}{l}\text { Radial and tangential eccentricities influence the net } \\
\text { circulation of the molten PCM. }\end{array}$ \\
\hline [45] & $\checkmark$ & $\checkmark$ & $\checkmark$ & & $\mathrm{N}$-eicosane & Horizontal & $\begin{array}{l}\text { Using eccentric } \\
\text { double pipe heat } \\
\text { exchanger. }\end{array}$ & $\begin{array}{l}\text { Radial eccentricity not only significantly enhances the } \\
\text { thermal performance of TES systems but also its } \\
\text { application is technically simple, economical and } \\
\text { practical. }\end{array}$ \\
\hline [46] & $\checkmark$ & & & & $\mathrm{N}$-eicosane & Horizontal & $\begin{array}{l}\text { Using eccentric } \\
\text { double pipe heat } \\
\text { exchanger. }\end{array}$ & $\begin{array}{l}\text { Faster melting occurred in the upper part of the inner } \\
\text { cylinder. }\end{array}$ \\
\hline [47] & & $\checkmark$ & & $\checkmark$ & $\begin{array}{l}\text { Paraffin } \\
\text { P56-58 }\end{array}$ & Horizontal & $\begin{array}{l}\text { Using eccentric } \\
\text { double pipe heat } \\
\text { exchanger. }\end{array}$ & $\begin{array}{l}\text { Rising radial eccentricity (either upward or } \\
\text { downward) increases discharging time. }\end{array}$ \\
\hline [48] & & & $\checkmark$ & & $\begin{array}{l}\text { Paraffin } \\
\text { P56-58 }\end{array}$ & Horizontal & $\begin{array}{l}\text { Using eccentric } \\
\text { double pipe heat } \\
\text { exchanger. }\end{array}$ & $\begin{array}{l}\text { Moving the inner tube toward the lowermost part of } \\
\text { the shell drastically reduces charging time. }\end{array}$ \\
\hline [49] & $\checkmark$ & & $\checkmark$ & & $\begin{array}{l}\text { Paraffin } \\
\text { RT50 }\end{array}$ & Horizontal & $\begin{array}{l}\text { Using eccentric } \\
\text { double pipe heat } \\
\text { exchanger. }\end{array}$ & \\
\hline
\end{tabular}




\begin{tabular}{|c|c|c|c|c|c|c|c|c|}
\hline Ref. & Study type & & Process & & PCM & Orientation & $\begin{array}{l}\text { Approach for } \\
\text { charging } \\
\text { improvement }\end{array}$ & Findings and conclusions \\
\hline & Numerical & Experimental & Charging & Discharging & & & & \\
\hline$[50]$ & $\checkmark$ & & $\checkmark$ & $\checkmark$ & $\begin{array}{l}\mathrm{N}- \\
\text { octadecane }\end{array}$ & Horizontal & $\begin{array}{l}\text { Using eccentric } \\
\text { double pipe heat } \\
\text { exchanger. }\end{array}$ & $\begin{array}{l}\text { There is an optimum radial eccentricity in a double } \\
\text { pipe TES. }\end{array}$ \\
\hline
\end{tabular}

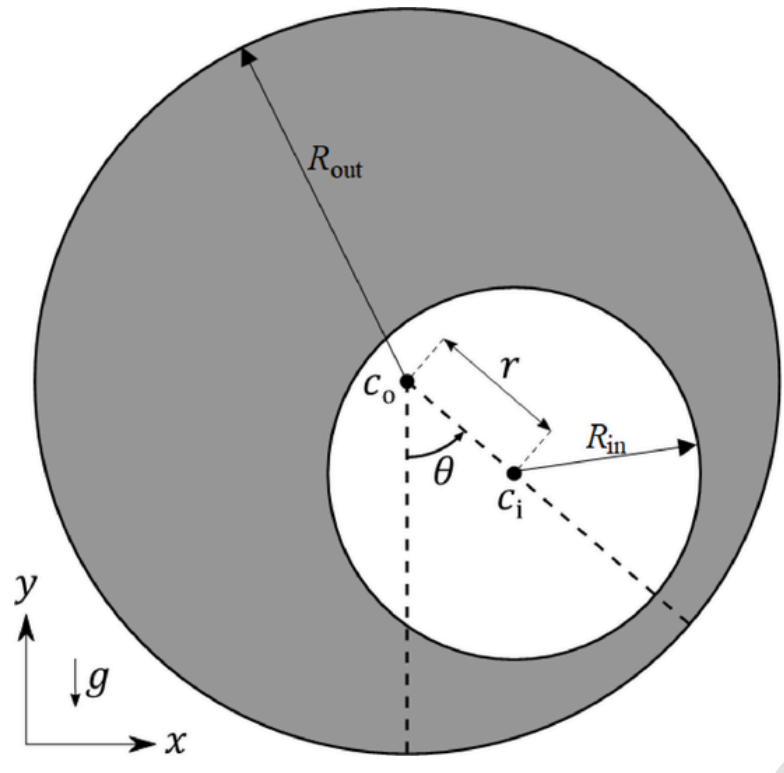

Fig. 1. Configuration of the horizontal eccentric-annulus.

\subsection{Optimisation problem}

As noted before, the geometrical parameters (radial and tangential eccentricities) and the associated geometric constraints (the inner diameter of outer cylinder and the outer diameter of inner cylinder) are defined in Fig. 1. The geometrical parameters and the associated bounds on parameters which form the design variable set for the optimisation problem are reported in Table 2. These bounds were defined based on the practical concerns and geometrical constraints in the design and construction of eccentric annuli.

The optimisation problem is formulated as follows:

Minimize/Maximize $\{$ charging time as function of $(\widetilde{x})\}$,

with $\tilde{x}=(r, \theta)$ subject to the bounds on the design-variable set $\widetilde{\mathrm{x}}$ listed in Table 2. In essence, this optimisation formulation finds the best configuration of the annulus to either have the quickest (maximum liquid fraction in a definite time) or slowest (minimum liquid fraction in a definite time) charging time.

Table 2

Definition of objective and parameter ranges.

\begin{tabular}{lll}
\hline Independent parameter & Lower bound & Upper bound \\
\hline Radial eccentricity $(r)[\mathrm{mm}]$ & $0.001\left(R_{\text {out }}-R_{\text {in }}\right)$ & $0.999\left(R_{\text {out }}-R_{\text {in }}\right)$ \\
Tangential eccentricity $(\theta)[\mathrm{rad}]$ & 0 & $\pi$ \\
\hline
\end{tabular}

\subsection{Computational fluid dynamics (CFD) modelling}

The CFD model was developed based on the thermofluid dynamics of energy storage systems which includes natural convection, conduction heat transfer and phase change during the charging process in the annulus. In the present study, the enthalpy-porosity formulation [51-53] was employed due to the benefits listed below.

- The solved governing equations for two phases are similar to single-phase flows.

- Instead of explicit tracking of the liquid-solid interface, an enthalpy-porosity formulation is solved.

- The enthalpy formulation includes the solution of both solid and liquid materials within a mushy zone between the two separate phases.

- This approach provides an easy implementation of phase-change problems.

In the enthalpy-porosity method, the liquid-solid mushy zone is treated as a porous zone where the porosity equals the liquid fraction. To take into account the pressure drop induced by the solid interface, appropriate momentum sink terms are added to the momentum equations. In the computation domain, each cell is associated with a quantity called "liquid fraction" calculated based on an enthalpy balance. In the mushy zone, modelled as a "pseudo" porous medium, the liquid fraction lies between 0 and 1 and the porosity decreases from 1 to 0 as the material solidifies. When the material is fully solidified in a cell, the porosity and hence the velocity drop to zero.

\subsubsection{Assumptions}

The thermofluid problem is simplified using the assumptions listed hereafter.

- The flow is 2-D, laminar, incompressible, transient and Newtonian.

- Due to the small variation of density, Boussinesq approximation is used for buoyant force calculations [34,36-38].

- The gravity direction is considered along the negative $y$-axis with a magnitude of $9.81 \mathrm{~m} / \mathrm{s}^{2}$ (see Fig. 1).

- Since large velocity gradients are not present in this study, viscous dissipation is neglected.

- Linear variation of the liquid fraction with temperature is assumed [34,36-38].

- Constant thermophysical properties for each phase are assumed except for the density, which is estimated based on the Boussinesq approximation.

- The outer surface of the outer cylinder is considered to be well insulated. Therefore, heat loss to the ambient environment is ignored. 


\subsubsection{Conservation equations}

For solidification and melting, the energy equation is written as follows:

$\frac{\partial}{\partial t}(\rho H)+\nabla \cdot(\rho \vec{v} H)=\nabla \cdot(k \nabla T)$

where $\rho$ is the PCM density, $v$ the velocity, $k$ the thermal conductivity, and $H$ the total volumetric enthalpy, that is the sum of sensible enthalpy, $h$, and latent heat, $L$ :

$H=h+f L$

$h=h_{\text {ref }}+\int_{T_{\text {ref }}}^{T} c_{\mathrm{p}} d t$

where $h_{\text {ref }}$ is the sensible enthalpy at the reference temperature, $T_{\text {ref, }}$ and $c_{\mathrm{p}}$ is the specific heat. $f$ refers to the liquid fraction given by Eq. (4):

$f=\left\{\begin{array}{cc}0 & T<T_{\text {solidus }} \\ \frac{T-T_{\text {solidus }}}{T_{\text {liquidus }}-T_{\text {solidus }}} ; & T_{\text {solidus }}<T<T_{\text {liquidus }} \\ 1 & T>T_{\text {liquidus }}\end{array}\right.$

In order to account for the effect of natural convection, the momentum equation is written as,

$\frac{\partial(\rho \vec{v})}{\partial t}+\nabla \cdot(\rho \vec{v} \vec{v})=-\nabla P+\nabla \cdot(\mu \nabla \vec{v})+\rho g+S$

where $\vec{v}$ is the velocity field, $P$ the pressure, $\mu$ the dynamic viscosity, and $S$ the momentum sink due to the reduced porosity in the mushy zone, which takes the following form:

$S=(1-f)^{2} /\left(f^{3}-?\right) v ? A_{m} u s h$

where the term $A_{\text {mush }}$ is a constant reflecting the mushy zone morphology that describes how steeply the velocity is reduced when the material solidifies. The constant $\varepsilon$ is a small number to prevent division by zero. The following parameters were used in this simulation [34,36-38]: $A_{\text {mush }}=10^{5}, \varepsilon=0.001$ and $T_{\text {ref }}=298.15$.

The Boussinesq approximation is applied: the density for the body force term is modelled based on a reference density $\left(\rho_{0}\right)$, temperature $\left(T_{0}\right)$, and the volumetric expansion coefficient $(\beta)$. Then the momentum equation is written as:

$$
\begin{aligned}
& \partial\left(\frac{\rho_{0} \vec{v}}{+}+\nabla \cdot\left(\rho_{0} \vec{v} \vec{v}\right)=-\nabla P \nabla \cdot(\mu \nabla \vec{v})\right. \\
& \left.\quad+\left(\rho-\rho_{0}\right) g+\frac{(1-f)^{2}}{f^{3}-\varepsilon} \vec{v} A_{\text {mush }}, \text { with }\right) \\
& \left(\rho-\rho_{0}\right) g=-\rho_{0} g \beta\left(T-T_{0}\right)
\end{aligned}
$$

The continuity equation is written as:

$\frac{\partial \rho}{\partial t}+\nabla \cdot(\rho \vec{v})=0$

The non-dimensional forms of governing equations obtain by considering the following non-dimensional parameters.

$$
\begin{gathered}
r^{*}=\frac{r}{D / 2}, \vec{v}^{*}=\frac{\vec{v} D}{\alpha}, T^{*}=\frac{T-T_{s}}{L / c_{p}}, \rho^{*} \frac{\rho}{\rho_{0}}, \nabla^{*}=D V, \\
P^{*}=\frac{P}{D^{2} / \rho a^{2}}, H^{*} \frac{H}{L}
\end{gathered}
$$

where $D=2\left(R_{\text {out }}-R_{\text {in }}\right)$ is the hydraulic diameter of annulus. $T_{\mathrm{S}}$ is the surface temperature of the inner cylinder, $T_{\mathrm{i}}$ is the initial temperature of the PCM, and $\alpha$ is the thermal diffusivity.
Then the non-dimensional form of the energy equation is written as follows:

$\frac{\partial\left(H^{*}\right)}{\partial F o}+\nabla^{*} \cdot\left(\vec{v}^{*} H^{*}\right)=\nabla^{*} \cdot\left(\nabla^{*} T^{*}\right)$

where $F o=\frac{\alpha t}{D^{2}}$ is the Fourier number.

The non-dimensional form of the momentum equation is written as:

$\frac{\partial\left(\vec{v}^{*}\right)}{\partial F_{o}}+\nabla^{*} \cdot\left(\vec{v}^{*} \vec{v}^{*}\right)=-\nabla^{*} P^{*}+\operatorname{Pr} \nabla^{*} \cdot\left(\nabla^{*} \vec{v}^{*}\right)$

$$
-\frac{\operatorname{RaPr}}{\operatorname{Ste}}\left(T^{*}-T_{0}^{*}\right)+C^{*} \vec{v}^{*}
$$

where $R a=\frac{g \beta\left(T-T_{s}\right) D^{3}}{\alpha \nu}$ is the Rayleigh number and $\operatorname{Pr}=\frac{v}{\alpha}$ is the Prandtl number. $\frac{\partial\left(\rho^{*}\right)}{\partial F o}+\nabla^{*} \cdot\left(\rho^{*} \vec{v}^{*}\right)=0$ are the Stefan number and the Dimensionless Darcy coefficient, respectively.

The non-dimensional form of the continuity equation is written as:

$\frac{\partial\left(\rho^{*}\right)}{\partial F_{O}}+\nabla^{*} \cdot\left(\rho^{*} \vec{v}^{*}\right)=0$

\subsubsection{Mesh generation}

The unstructured tetrahedral mesh was generated in ANSYS-Meshing 19. Different grid sizes were examined to ensure the solution independency from mesh topology by comparing the temporal variations in the liquid fraction over selected grid sizes of 1185, 4553, 6615 and 8541 nodes. An arrangement of 6615 nodes was then found sufficient for the present study. Fig. 2 presents a sample of mesh for the case with $r^{*}=0.841$ and $\theta=0.029 \pi$. This mesh arrangement requires an element size of $0.3 \mathrm{~mm}$, which presents high-quality unstructured mesh resolutions with average orthogonal quality and skewness of 0.987 and 0.085 , respectively. For the symmetric cases, only half of the geometry is simulated.

\subsubsection{PCM thermophysical properties and boundary conditions}

The thermophysical properties of the PCM used in this work are listed in Table 3. During the initial studies, n-eicosane is taken as

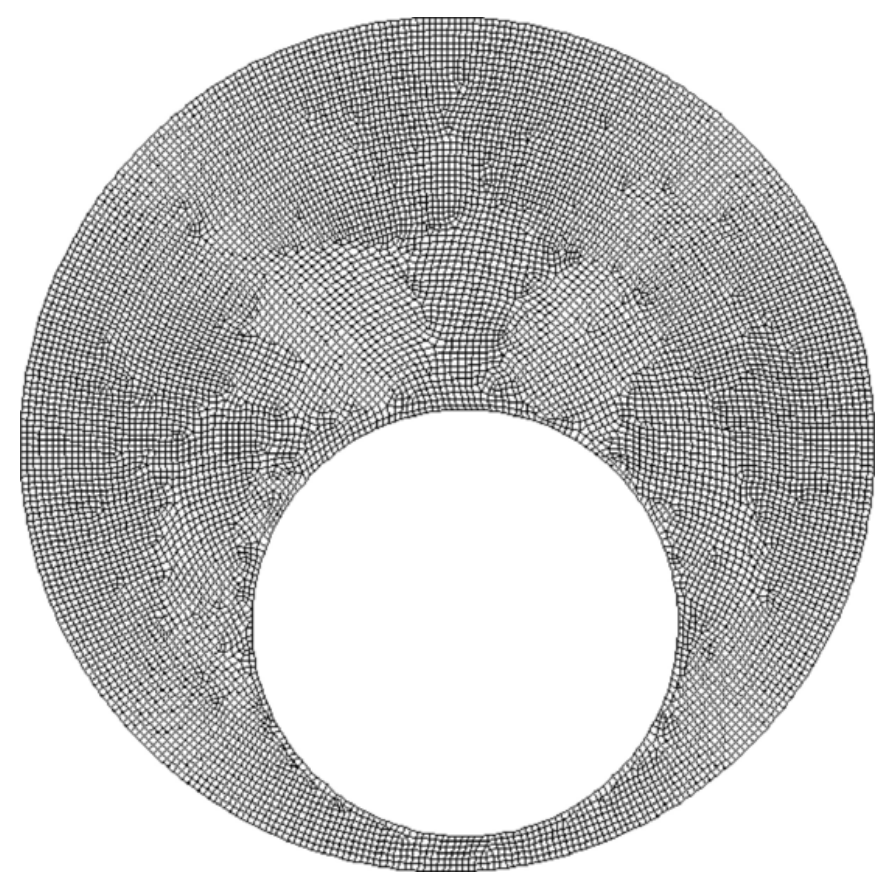

Fig. 2. Mesh of the proposed computational domain $r^{*}=0.841$ and $\theta=0.029 \pi$. 
Table 3

Thermophysical properties of the PCMs [46-54].

\begin{tabular}{lllll}
\hline Property & RT31 & RT35 & RT44HC & $\begin{array}{l}\text { N- } \\
\text { eicosane }\end{array}$ \\
\hline Solidus temperature $\left[{ }^{\circ} \mathrm{C}\right]$ & 300.15 & 302.15 & 314.15 & 308.15 \\
Liquidus temperature $\left[{ }^{\circ} \mathrm{C}\right]$ & 306.15 & 309.15 & 317.15 & 310.15 \\
Liquid density $[\mathrm{kg} / \mathrm{m} 3]$ & 760 & 770 & 700 & 770 \\
Specific heat capacity $[\mathrm{J} / \mathrm{kg} \bullet \mathrm{K}]$ & 2000 & 2000 & 2000 & 2460 \\
Latent heat of fusion $[\mathrm{kJ} / \mathrm{kg}]$ & 170 & 160 & 250 & 247.6 \\
Thermal conductivity $[\mathrm{W} / \mathrm{m} \bullet \mathrm{K}]$ & 0.2 & 0.2 & 0.2 & 0.1505 \\
Thermal expansion coefficient & 0.00076 & 0.00076 & 0.00076 & 0.0009 \\
{$[1 / \mathrm{K}]$} & & & & \\
Dynamic viscosity $[\mathrm{kg} / \mathrm{m} \bullet \mathrm{s}]$ & 0.002508 & 0.0025 & 0.0033 & 0.00385 \\
\hline
\end{tabular}

the PCM, while the complementary studies also consider the effects of using other materials. Variations in thermophysical properties other than the density have been ignored [34,36-38]. While the inner cylinder is kept at a constant temperature, the outer cylinder is considered adiabatic in all cases. The PCM material is initially sub-cooled for charging or superheated for discharging by $1 \mathrm{~K}$ as well. It is assumed that the surface temperature of the inner cylinder is $20 \mathrm{~K}$ above the initial temperature of the solid PCM in charging and $20 \mathrm{~K}$ under the initial temperature of the solid PCM in discharging for all cases.

\subsubsection{CFD model settings}

ANSYS-Fluent 19 is employed for solving the set of coupled partial differential governing equations. Based on the control volume technique, the Pressure Implicit with Splitting of Operator (PISO) algorithm is used for treating the pressure-velocity coupling. The discretization of momentum and energy equations is performed by the QUICK differencing scheme, while the PRESTO! (PREssure STaggering Option) scheme is adopted for the pressure correction. A first-order implicit time advancing method is used and at each time step with constant size of $0.01 \mathrm{~s}$, a course of 60 iterations were found satisfactory to fulfil the convergence criteria of less than $10^{-6}$ for all equations.

To achieve a stable solution through iterations, the under-relaxation factors for the velocity components, pressure correction and liquid fraction were set, respectively, to $0.4,0.3$, and 0.9 while density, body force, and energy under-relaxation factors are fixed to a value of 1 .

\subsection{Optimisation methods (algorithm and model settings)}

For this optimisation study, ANSYS DX (DesignXplorer) was used. ANSYS DX is a mathematical optimisation tool based on the response surface method. To construct the response surfaces, design of experiments (DOE) is performed to generate design points. In this study, 15 auto-defined custom and sampling design points were determined for 2 defined independent parameters. For each of those samples, CFD simulations were run individually and the corresponding information of the objective (charging time of the TES) was extracted at a definite time that is the shortest time required to fully charge one of the generated design points. A non-parametric regression response-surface type was then constructed for the output parameter and combined. The determination of the optimum location of these surfaces (candidate points) was performed by using a screening approach, followed by a non-linear programming by quadratic Lagrangian (NLPQL) algorithm. The screening method is a non-iterative direct sampling method based on the Hammersley algorithm. This method determines the starting values (initial guesses) for the NLPQL method, which is a mathematical optimisation algorithm and generates a new candidate set based on the provided initial guesses (candidate points of screening method). Indeed, the
NLPQL algorithm is the complementary of the screening method and provides a more refined approach than the screening alone.

The settings of the optimisation approach are presented hereafter. The screening method settings were set to 1000 samples, while the NLPQL method settings were "Central", $10^{-4}$ and 20 for "Finite Difference Approximation", "Allowable Convergence" and "Maximum Number of Iterations", respectively. The optimisation process terminates whenever either the allowable convergence or the maximum number of iterations is reached.

For more information on the design point generations, optimisation approaches, meaning of these optimisation settings, and in general optimisation process in ANSYS DX, the interested author can refer to ANSYS DX help [55] and Ref. [56-59].

\section{Results and discussion}

\subsection{Validation}

Firstly, in order to evaluate the accuracy of the enthalpy-porosity method with consideration of natural convection that is employed in the present work, numerical predictions regarding the melting characteristics and front track of the melted region are compared with experimental results from Dhaidan et al. [45]. In particular, this involved the simulation of a horizontal concentric double-pipe TES comprising an aluminium tube with an inner diameter of $16.1 \mathrm{~mm}$ and a thickness of $1.5 \mathrm{~mm}$ within a Plexiglas shell with a diameter of $44.5 \mathrm{~mm}$ and a thickness of $3.15 \mathrm{~mm}$, filled with pure n-octadecane as the PCM that is initially subcooled by $5.3 \mathrm{~K}$. The thermophysical properties of n-octadecane and aluminium can be found in Ref. [45], while the thermophysical properties of Plexiglas can be found in Ref. [37]. A heat flux of $1821.3 \mathrm{~W} / \mathrm{m}^{2}$ was imposed at the inner surface of the inner pipe. Fig. 3 shows comparisons between numerical predictions from our model against experimental and numerical results in the literature, for the prediction of the melting front of the PCM at selected times during the melting process. In this figure, numerical results from the present study are shown on the right-hand side of the images, while the visualized melting front from the experiment along with the numerical prediction of the melting front simulated by Dhaidan et al. [45] (blue dashed lines), are displayed on the left-hand side. It can be observed that the model used in this present paper can predict correctly the effect of natural convection on the melting front in an annular TES.

Moreover, predictions from the present CFD simulations were compared to results reported by Darzi et al. [46], which also relate to a concentric circular annulus filled with n-eicosane. The thermophysical properties of n-eicosane can be found in Table 3. For this exercise, the inner and outer TES cylinder diameters were set to 20 and $40 \mathrm{~mm}$, respectively. The PCM was initially subcooled at $1 \mathrm{~K}$, while the temperature of the inner TES cylinder was fixed to $329.15 \mathrm{~K}$.

Fig. 4 compares the variation of liquid fraction between the present results and those of Darzi et al. [46], that are observed to be in good agreement. It is worth noting that the work of Darzi et al. [46] had also been later validated against data obtained by Dhaidan et al. [45].

Finally, the accuracy of the enthalpy-porosity method for predicting the solidification characteristics was validated against experimental data found in Seddegh et al. [60], where a horizontal double-pipe TES was considered comprising an annulus with inner and outer diameters of $22 \mathrm{~mm}$ and $85 \mathrm{~mm}$, respectively. This TES was filled with pure paraffin RT55 as the PCM. The thermophysical properties of RT55 can be found in Ref. [60]. The initial temperature of the PCM was $343 \mathrm{~K}$, and the HTF temperature was set at $293 \mathrm{~K}$. The convective boundary condition was imposed on the inner surface of the annulus (according to Ref. [60]), while the outer surface of the annulus considered to be thermally insulated. In Fig. 5, the PCM temperature and liquid fraction during the solidification process predicted by the present 


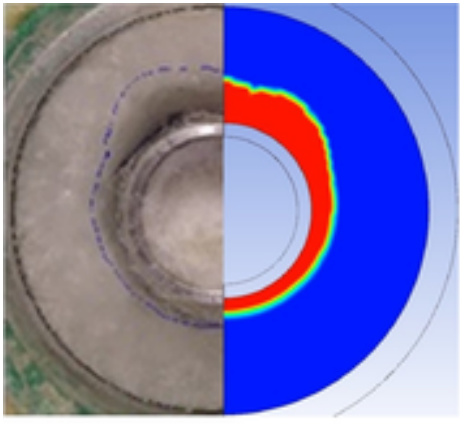

$20 \mathrm{~min}$

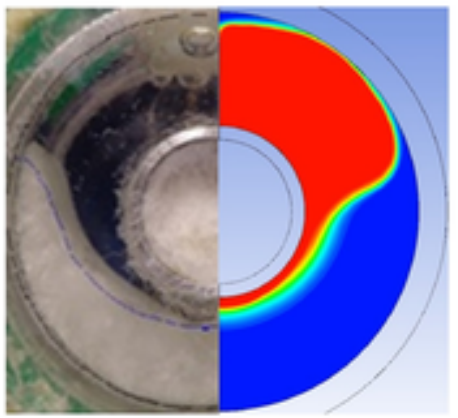

$50 \mathrm{~min}$

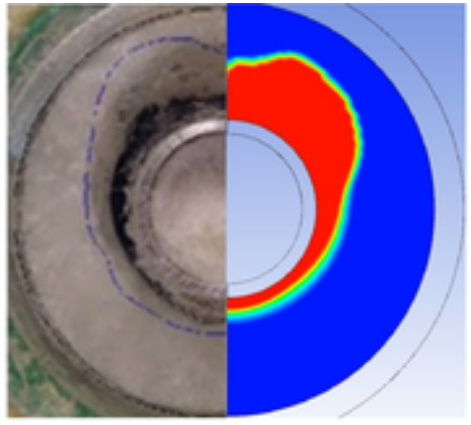

$30 \mathrm{~min}$

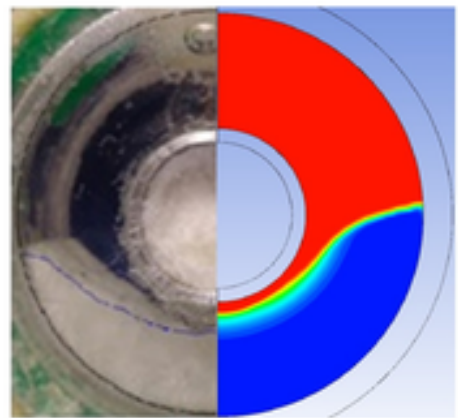

$60 \mathrm{~min}$

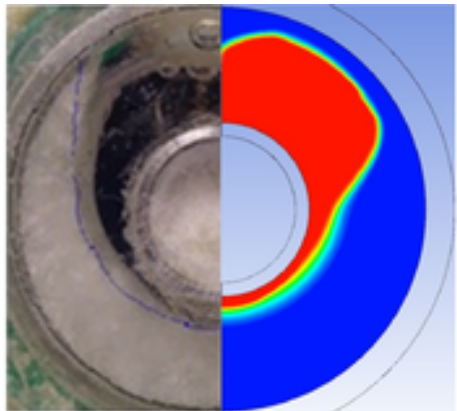

$40 \mathrm{~min}$

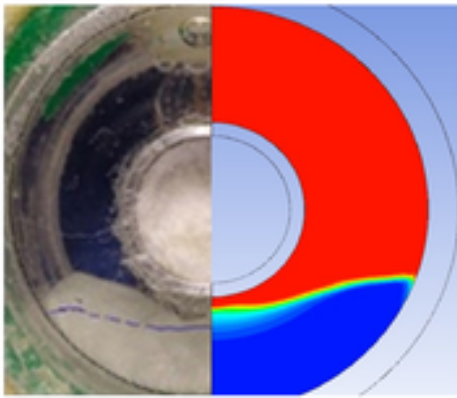

$70 \mathrm{~min}$

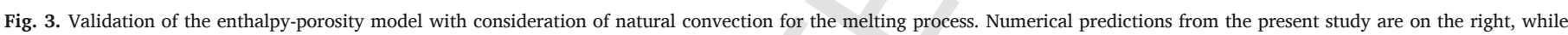
numerically predicted and experimentally visualized melting fronts from Ref. [45] are on the left.

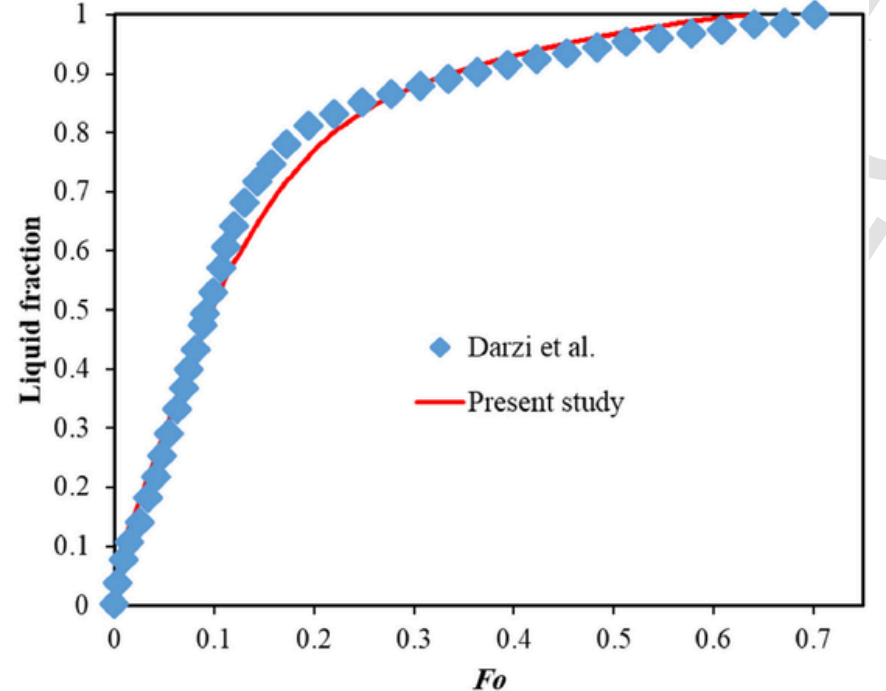

Fig. 4. Validation of melting process simulations against Darzi et al. [46]

numerical model are compared to those associated with the experiments performed by Seddegh et al. [60]. It can be seen that the temperature profile estimated by the numerical model of this study is in a close agreement with the experimental data obtained during solidification.

\subsection{Optimisation}

The response surfaces of the optimisation problem were generated based on a non-parametric regression, which leads to the best goodness of fit for this problem. This goodness of fit of the response surfaces predicted by this method versus actual calculated sampling data (design points) is shown in Fig. 6. The RMS error and the relative

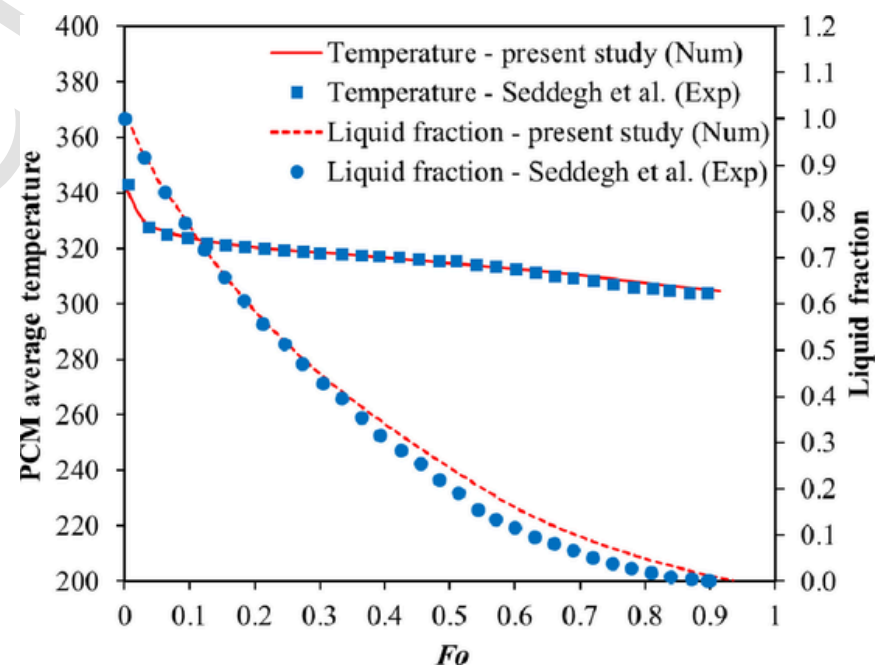

Fig. 5. Validation of solidification process simulations against Seddegh et al. [60].

average maximum absolute error of this surface fit are 0.005 and $3 \%$, respectively. Therefore, this method generates a response surface with an acceptable accuracy (Fig. 7) that can be used for the optimisation process.

The optimisation on the generated response surfaces converged after 1000 iterations for screening approach and 5 iterations for the NLPQL approach. To show the effect of independent parameters on the objective of the optimisation problem, a response surface is shown in Fig. 7. It is noted that the optimisation study is more sensitive to tangential eccentricity; therefore, the response surface variations based on tangential eccentricity are much sharper than that for radial eccentricity. In addition, higher radial and tangential eccentricities (placing the inner tube at almost the furthest radial and tangential distances, 


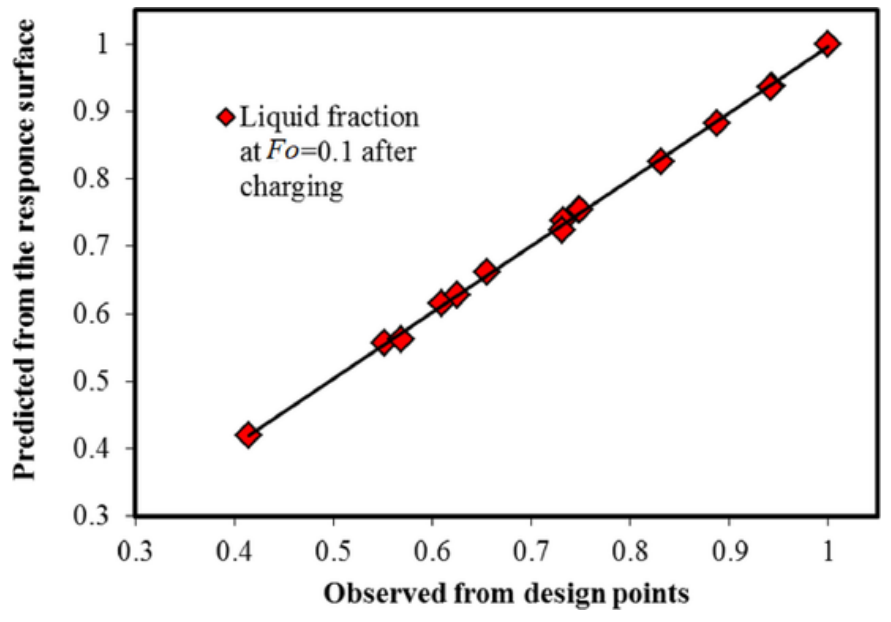

Fig. 6. Goodness-of-fit presented by ANSYS DX.

which are the furthest possible radial positions along the positive $y$-axis) decrease the charging ability of the TES and consequently decrease generated liquid faction of the PCM in the domain. This trend can be attributed to the fact that increasing eccentricities (i.e., placing the inner tube right above the centre) creates less room for plum formations due to natural convection, which in turn decreases the intensity of the buoyant flow and natural convection. Therefore, one can expect that the charging time drastically decreases. Furthermore, as illustrated in Fig. 7, higher radial and lower tangential eccentricities (i.e., placing the inner tube at the furthest radial position, yet not necessarily along the negative $y$-axis) increase the charging speed. This fact can also be attributed to the augmentation of both plum formations and buoyant force due to the geometrical asymmetry, which will be discussed in more details. Therefore, according to the constructed response surface, the rate of PCM melting would be favourably improved at such positions.

Table 4 reports the values of utopian points among all feasible Pareto optimal cases of quickest and slowest charging time of the proposed TES. The optimal set of parameters (optimum results) obtained in response surface optimisation approaches, were fed into the CFD model to compute the actual results of charging time, listed as objectives in Table 4.

\subsection{Melting process (charging TES) with n-eicosane}

In this section, the behaviour of the proposed storages filled with n-eicosane during the charging process is studied. Fig. 8 illustrates the computational liquid fraction of the proposed optimum eccentric annuli (that are the slowest and quickest melting charges) and the concentric annulus (baseline case) at different instants. As shown, all annuli initially melt approximately with the same rate and the amount of molten PCM is almost similar. Further, charging speeds up the melting of PCM due to the dominance of natural convection. This heat transfer mechanism plays a substantial role in charging all the cases until all the PCM above the inner cylinder is melted. Then, the influence of natural convection is diminished and the contribution of heat diffusion enhanced. As the inner cylinder shifts to the lowermost and uppermost parts of the outer cylinder, the buoyancy-driven flows and heat flow rates are affected, so that these two configurations respectively correspond to the quickest and slowest cases.

Fig. 9 illustrates the streamlines and isotherms of the proposed optimum annulus and the baseline case at various instants. For sake of brevity and due to symmetrical geometries of the baseline and the slowest cases, both streamlines and isotherms of each instant are respectively presented in the left- and right-hand sides of one image. Owing to natural convection, the convection cells stir the molten PCM, thus preventing stratification of the PCM temperature distribution.

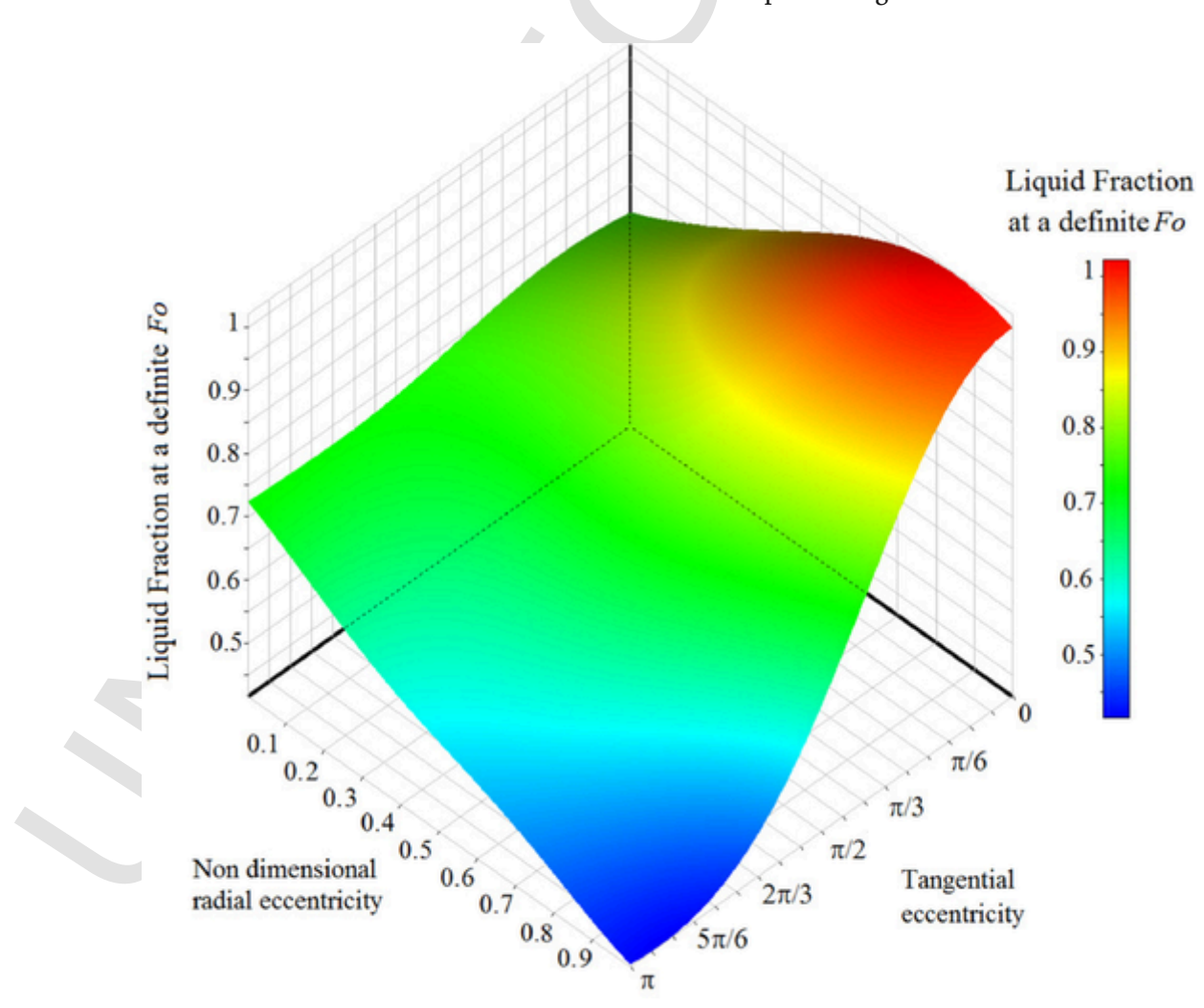

Fig. 7. 3-D response surface of liquid fraction at a definite Fo (z-axis) versus non-dimensional radial eccentricity ( $x$-axis) and tangential eccentricity ( $y$-axis). 
Table 4

Candidate utopian points.

\begin{tabular}{|c|c|c|c|}
\hline \multirow[t]{2}{*}{ Parameters } & \multicolumn{2}{|c|}{ Optimum eccentric cases } & \multirow[t]{2}{*}{$\begin{array}{l}\text { Concentric } \\
\text { (base) case }\end{array}$} \\
\hline & $\begin{array}{l}\text { Quickest melting } \\
\text { charge }\end{array}$ & $\begin{array}{l}\text { Slowest melting } \\
\text { charge }\end{array}$ & \\
\hline $\begin{array}{l}\text { Radial eccentricity } \\
\left(r^{*}\right)\end{array}$ & 0.841 & 0.999 & 0 \\
\hline $\begin{array}{l}\text { Tangential } \\
\text { eccentricity }(\theta)[\mathrm{rad}]\end{array}$ & $0.029 \pi$ & $\pi$ & 0 \\
\hline Objective & Calculated & Calculated & Calculated \\
\hline $\begin{array}{l}\text { Required Fo to full } \\
\text { charge }\end{array}$ & 0.09 & 2.31 & 0.64 \\
\hline
\end{tabular}

This region in the isotherms images of Fig. 9 is shown in red above the inner cylinder. However, the natural convection and circulations in the rest of the TES domain are suppressed by conduction, which mainly occurs in the solid region, shown in blue below the inner cylinder in all isotherms images in Fig. 9. The transition from the natural convection dominated region (red regions in all isotherms images in Fig. 9) to the diffusion-governed zone (blue regions in all isotherms images in Fig. 9), takes places across a region governed by mix of weak natural convection and conduction region, characterised by a stratified temperature field, that appears as a rainbow-like region in all isotherms of Fig. 9.

To show clearly these three distinct regions (convection dominant, mix weak convection and conduction and conduction dominant), graphically, the streamlines, isotherms and liquid fraction of the slowest geometry at $F o=0.60$ are shown side by side in Fig. 8 . The three regions of melting shown in Fig. 10 phenomenologically confirm the findings of Wang et al. [42], who have shown that the charging process comprises three stages: (i) a rapidly charging period, (ii) a slowly charging period; and (iii) an even more slowly charging period. At the first stage of the melting process, due to strong buoyancy-driven dynamics, a fast phase-change rate prevails. The second period is characterised by weak convective effects, while the last one is dominated by thermal diffusion. Unlike the concentric and slowest configurations, the quickest configuration (i.e., with the inner cylinder placed at the lowermost part of the outer cylinder) favours the development of convection cells, thus allowing a buoyancy-driven convective heat transfer to be sustained during the charging process. Fig. 9 confirms the findings of Dutta et al. [44] and Dhaidan et al. [45], who observed that the contributions of both the radial and tangential eccentricities contribute to the net circulation of the molten PCM.

Fig. 11 compares the charging behaviour of the concentric annulus (i.e., the baseline case) with the optimum eccentric annuli (i.e., the geometries with the quickest and slowest melting charges). As discussed in Appendix A, the liquid fraction of these cases (as shown in Fig. 11) is a similar alternative for energy storage rate of the TESs which can be used interchangeably in this study. In each curve, the straight line with steep slope represents the convection dominant zone of that geometry in which a higher rate of melting can be observed. In the eccentric annulus with the slowest melting charge, only $20 \%$ of the melting occurs in the convection dominant zone. In the concentric annulus, roughly $65 \%$ of the melting takes place in this zone. Surprisingly, in the eccentric annulus of quickest melting charge, almost all the PCM melts in the convection dominant zone, thus significantly reducing the charging time. In fact, the optimisation process modifies the position of the inner cylinder to increase the region affected by natural convection.

Most studies investigating the impact of the inner-tube eccentricity on the melting and solidification processes of a PCM in annuli (e.g., those presented in Refs $[46,47,49]$.) focus on the impact of the radial eccentricity, while the effect of the tangential eccentricity has never been discussed in detail, to the best of authors' knowledge. Moreover, the influence of the eccentricity is explored through parametric analyses in the cited work. With a simultaneous optimisation of both eccentricities, the present study provides us with the global optimum position of the inner tube that favours quick (or slow) melting (or solidification) of the PCM.

The results of this optimisation shows that this optimal position is near the maximum radial eccentricity ( $\left.r^{*}=0.841\right)$ with a small angle offset from the vertical axis $(\theta=0.029 \pi)$. A parametric study is conducted, whereby the position of the inner tube is varied around its optimum. Two additional cases are simulated, namely cases 2 and 3 as shown in Fig. 12. Placing the inner tube on the vertical axis at the same radial eccentricity (case 2) results in a longer charging phase, with a melting time $11 \%$ higher than that with the optimum configuration, while increasing the radial eccentricity to its maximum (case 3) leads to a further increase of the charging time. This demonstrates that the optimum eccentricity has to be

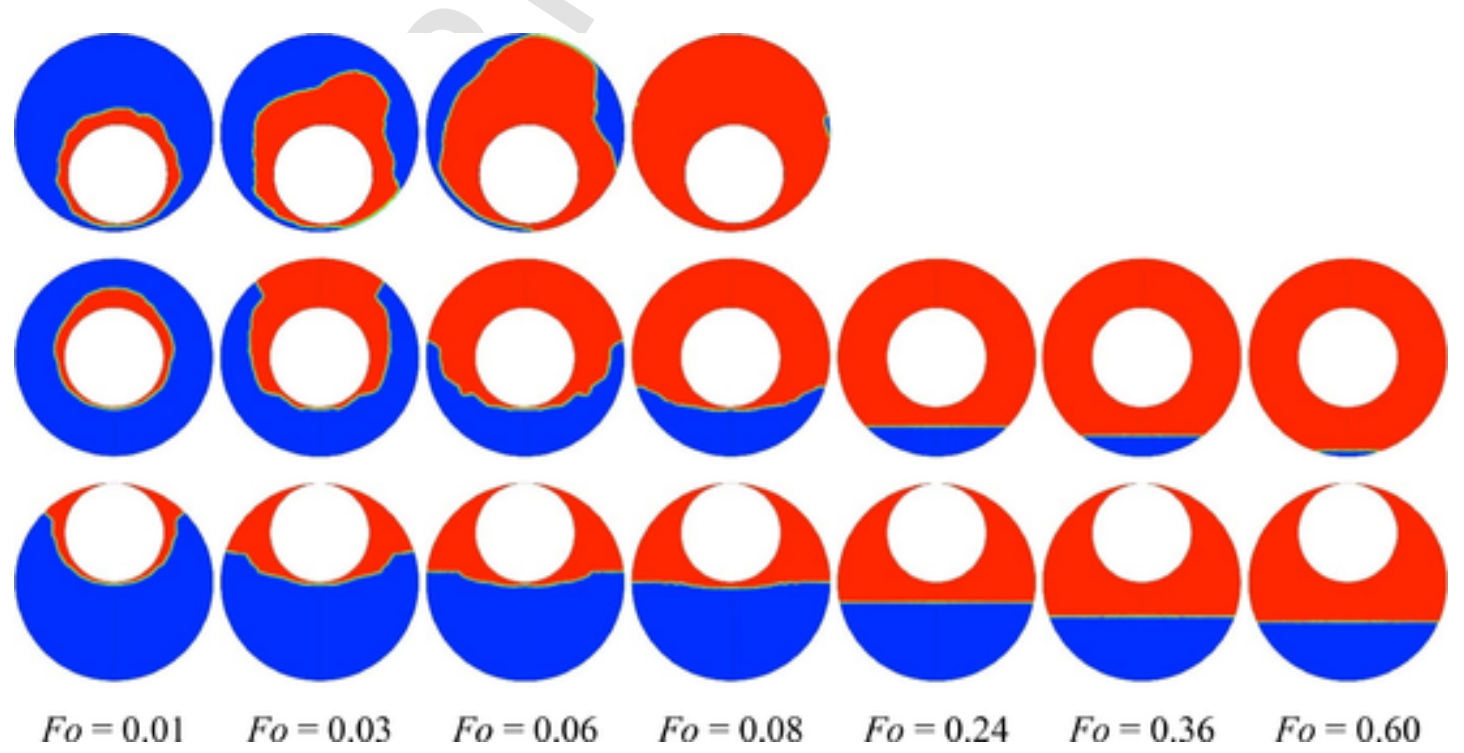

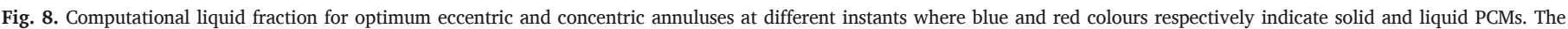
first, second and third rows respectively dedicate the quickest, base and slowest geometries. 


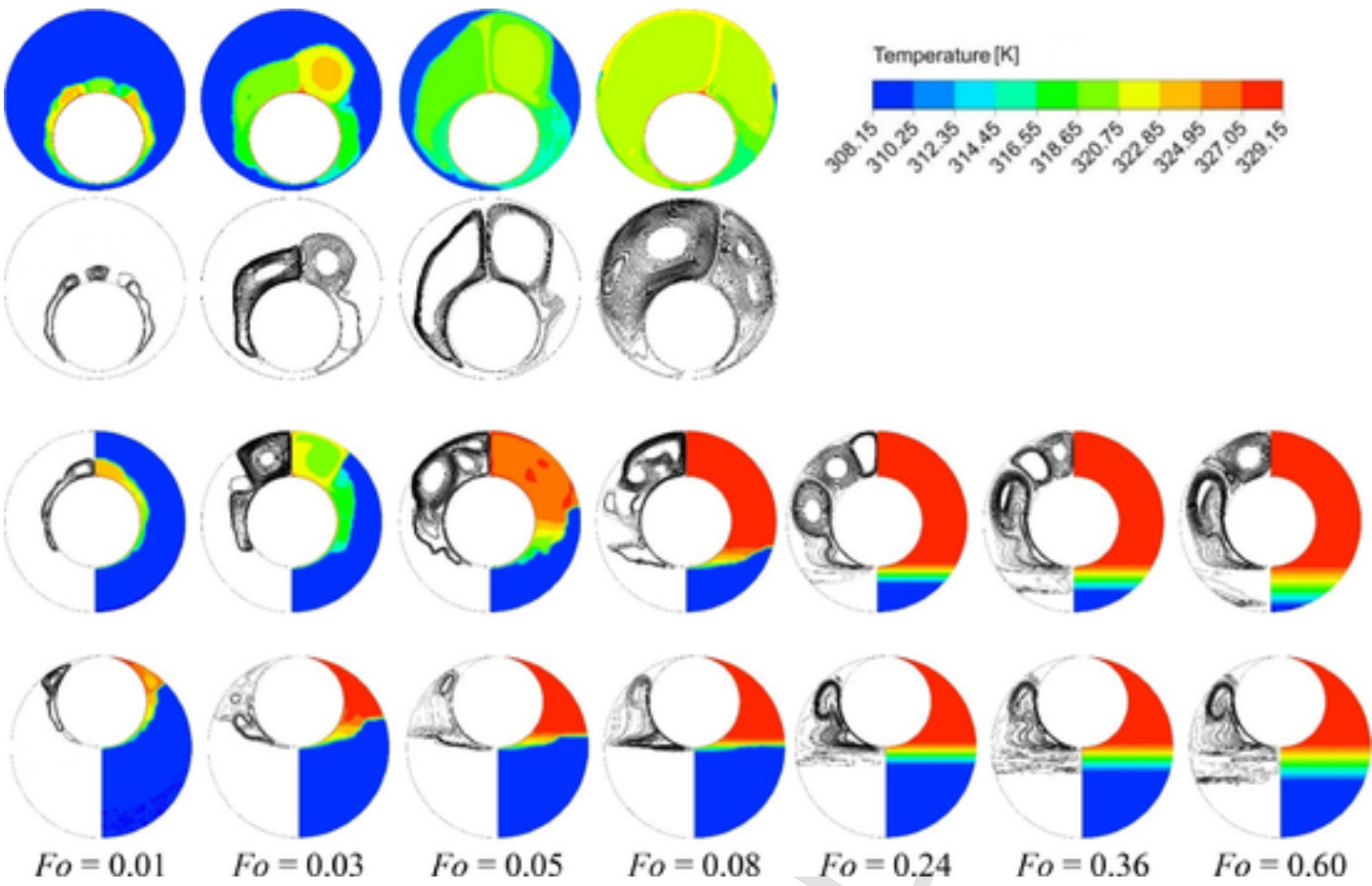

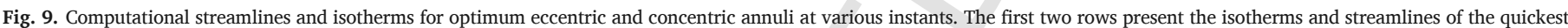

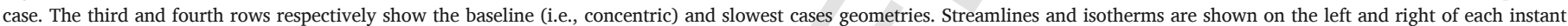
image, respectively.

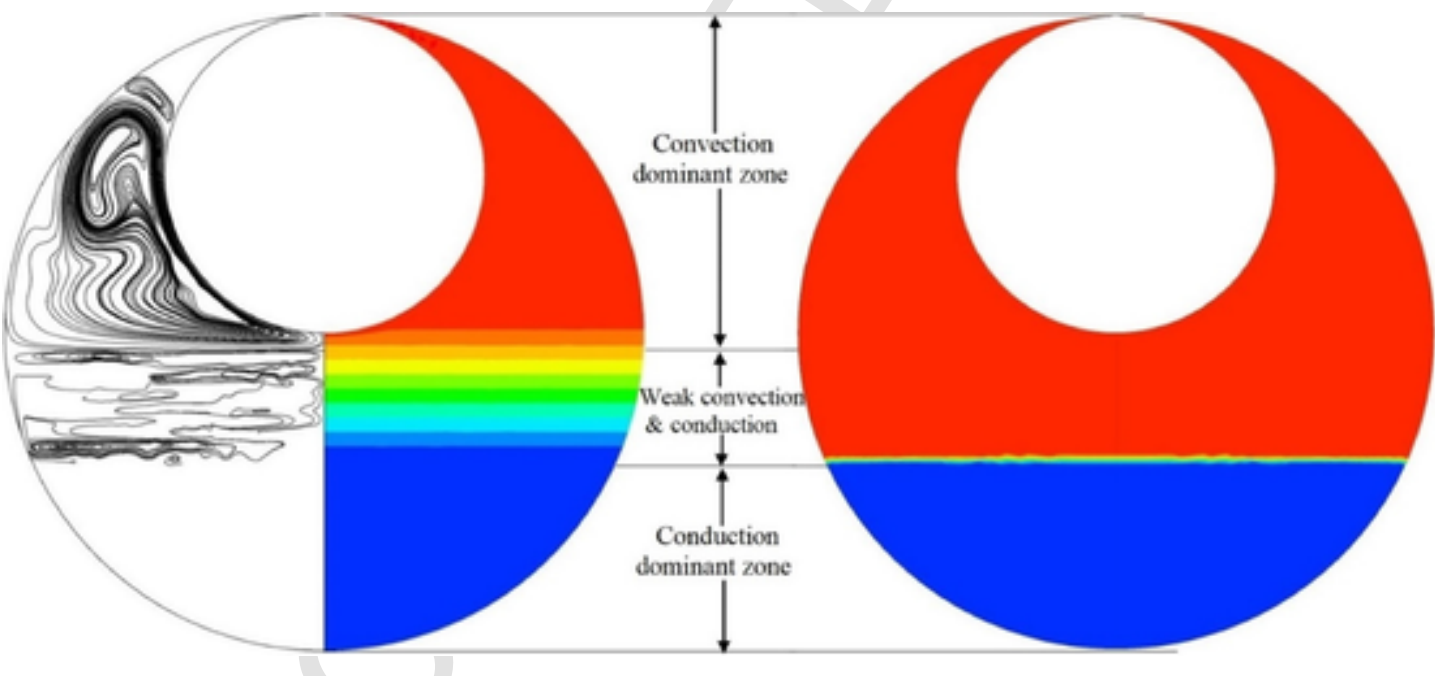

Fig. 10. Three different heat transfer mechanisms for slowest geometry at Fo $=0.60$; shown, from left to right, are streamlines, isotherms and liquid fraction.

determined carefully, as placing the inner tube in utopian external positions does not ensure maximum performance. This also reinforces the confidence in the numerical methods implemented, as small variations around the optimum identified systematically incur a performance decrease.

Fig. 13 compares the energy storage rate per unit mass of PCM in the concentric and proposed optimum annuli filled with n-eicosane. In the initial stage of charging, optimum annuli have a similar energy storing rate, which is higher than that of the concentric annulus. However, as time passes during the charging process, the annulus with the quickest melting charge exhibits the highest storage rate. This is followed by the concentric-annulus arrangement, while the slowest-melting optimum demonstrates the lowest rate of energy storage.

\subsection{Solidification process (discharging TES) with n-eicosane}

In this section, the behaviour of the proposed storages filled with n-eicosane during the discharging process is studied. Fig. 14 illustrates the liquid fraction (or phase) distribution for the proposed optimum eccentric annuli and the concentric annulus at different instants. The solidification starts uniformly around the inner cylinder and the solidification front then propagates radially for all annuli, which causes the molten PCM to solidify at similar rates during the initial steps. For the concentric annulus (base case), the freezing front displacement then remains radial until all molten PCM is solidified, while, for the optimum annulus configurations, the solidification front later propagates in the vertical direction (upward for the annulus with quickest melting charge and downward for the annulus with the slowest melting charge). 


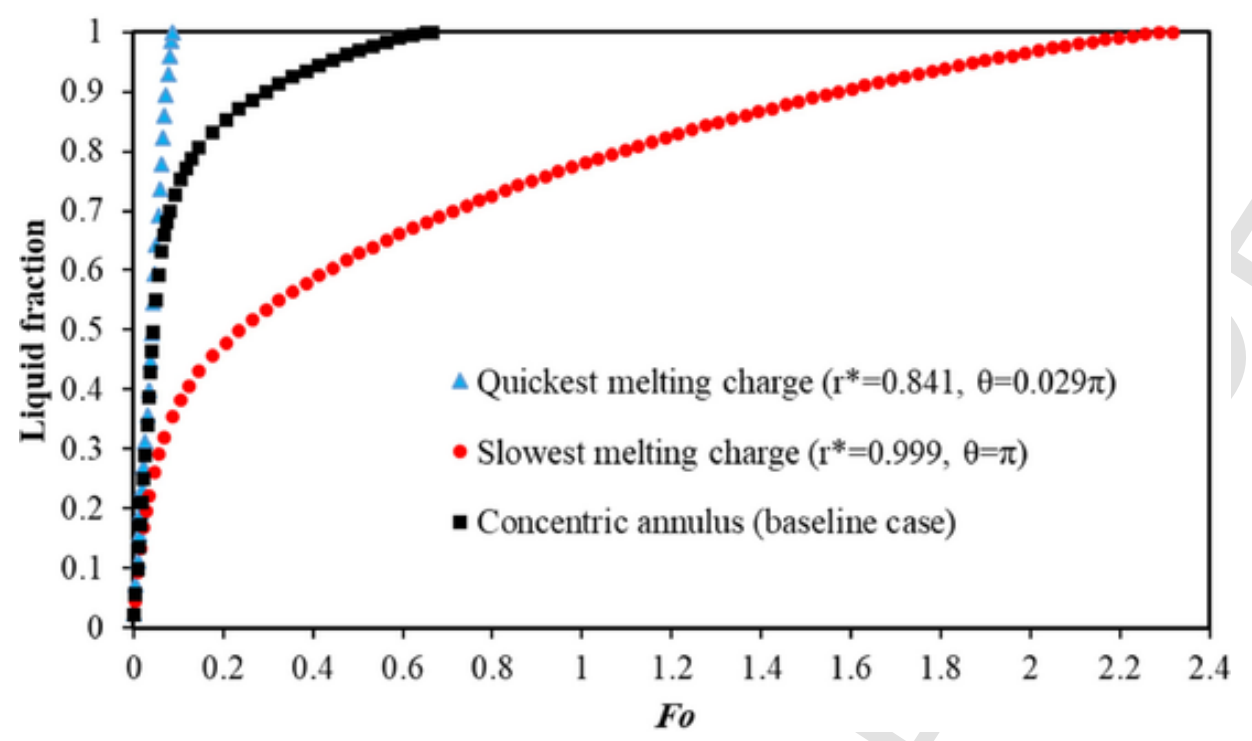

Fig. 11. Comparison of the charging rates in the concentric and optimum eccentric annulus configurations.

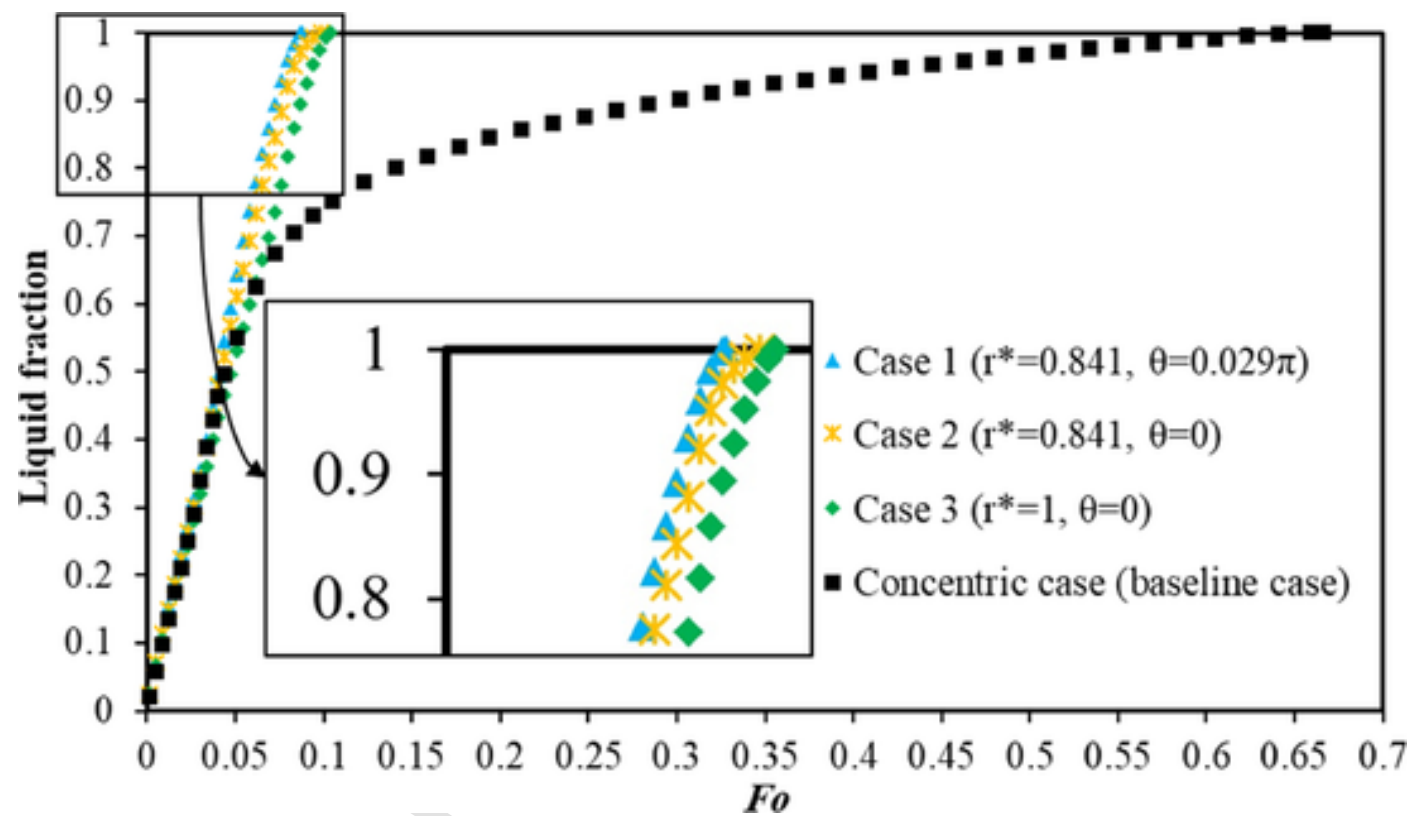

Fig. 12. Comparison of the influence of optimum eccentricity parameters.

The propagation trends of the solidification front in optimum and concentric annuli demonstrate that this process is mainly dominated by conductive heat transfer and that convection is negligible. The decline in the solidification rate observed for the optimum configurations (i.e., with the inner cylinder placed in the uppermost and lowermost positions) can be explained: (i) by a reduced interface between the molten and solid PCM in comparison with the concentric case, and (ii) by a decrease with time of the phase-change front area.

Fig. 15 shows isotherms of the proposed optimum annuli and the baseline case at various instants. The rainbow-like configurations in all images of Fig. 15 reveal that the temperature distributions are nearly stratified during the whole solidification process, which reflects diffusion-dominated heat transfer mechanisms. Unlike for the charging phase, it is thus of little interest to show the streamlines along with the isotherms, as no gradient would be noticeable. Just as was observed on the phase distribution patterns in Fig. 14, the temperature maps reported in Fig. 15 show clearly that the phase-change front spreads radially in the baseline configuration, while it propagates vertically for most of the discharging process in the optimum annuli.

Fig. 16 compares the solidification rates of the concentric annulus with those of the proposed optimum eccentric annuli. In the baseline case, the entire PCM freezes at $F o=0.99$, while the solidification of the PCM in the so-called optimum configurations lasts approximately three times as much (i.e., $F o=2.83$ and $F o=2.98$ ). It is worth noting that the freezing rates are found to be similar for all cases during the first instances until $F o=0.12$, while the solidification rate remains almost constant until the end of the discharging process in the baseline case, which is consistent with the qualitative analyses of Fig.s 14 and 15 proposed before. Likewise, similar solidification rates are observed for the two optimum configurations (i.e., cases with slowest and quickest charging phases), that are slower than in the baseline case and decrease as the phase-change front propagates and gradually reduces. These results match the findings of Zhang and Faghri [43] and Yazici et al. [47], who found that moving the tube upward/downward according 


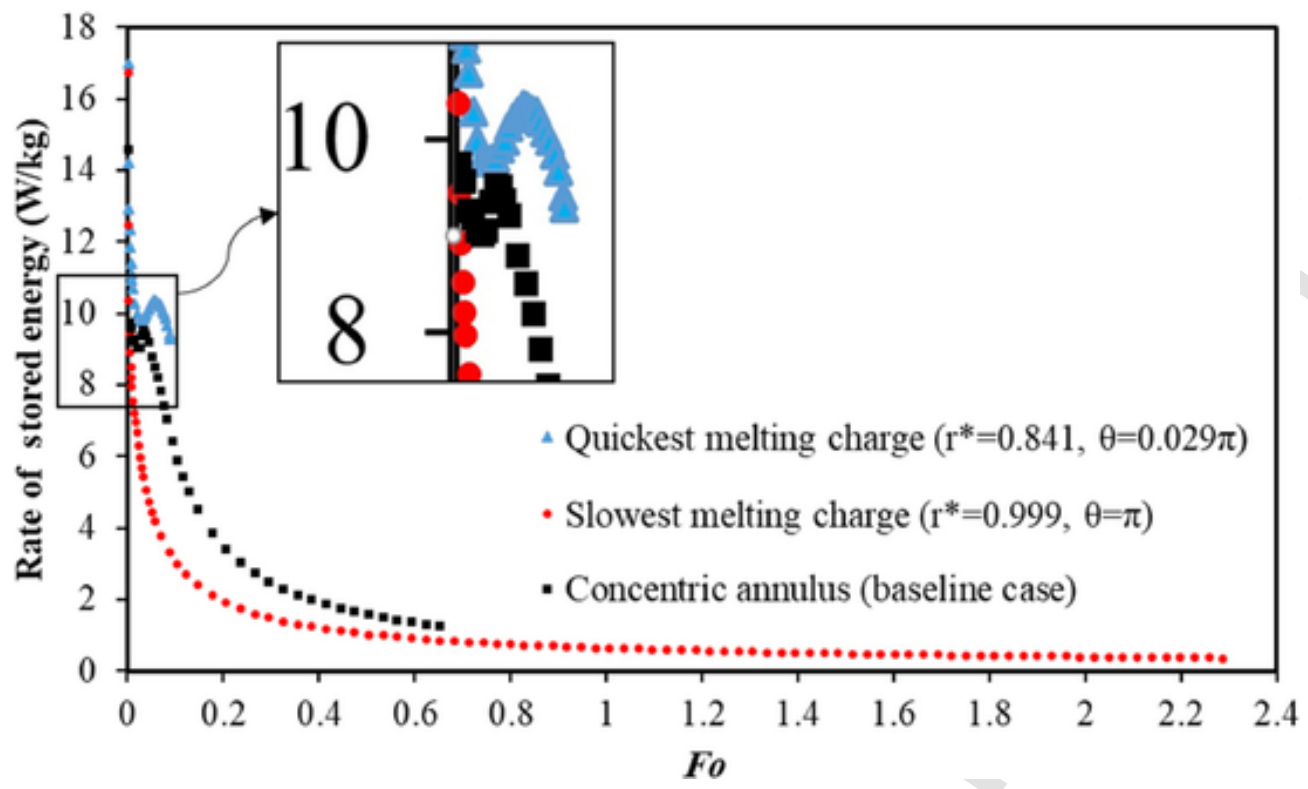

Fig. 13. Comparison of the rate of stored energy in the concentric and optimum eccentric annulus configurations.
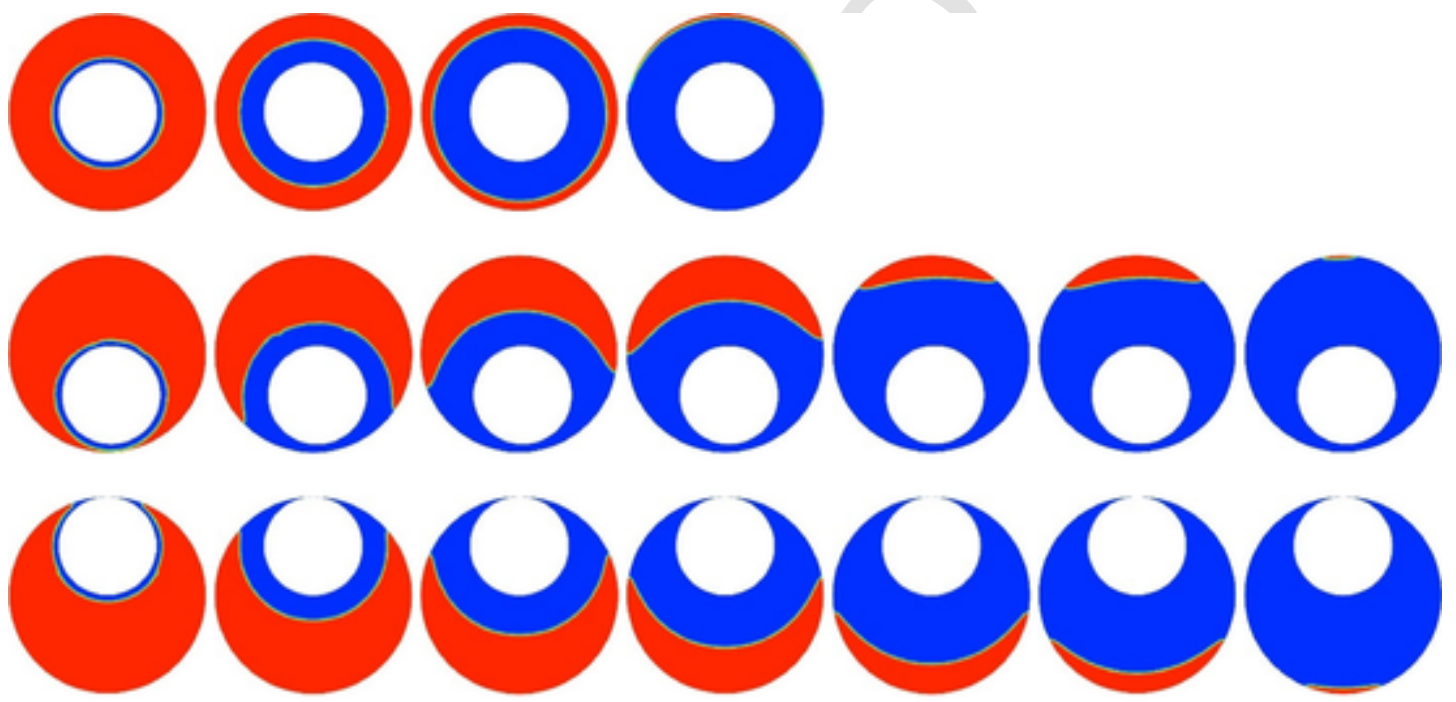

$F o=0.01$

$F O=0.19 \quad F O=0.48$

Fo $=0.83$

$F o=1.43$

$F o=1.91$

Fo $=2.74$

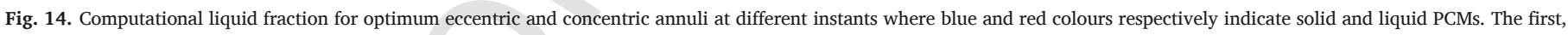
second .

to the centre of the shell (increasing the radial eccentricity) acts to augment the total discharge time due to the dominant role of conduction in the charge process. However, for the same reason, fast transmission of the stored energy is achievable by a concentric double-pipe TES.

Fig. 17 compares the rate of released energy per unit mass of PCM in concentric and optimum annuli filled with n-eicosane. At the beginning of the discharge process, the concentric annulus and the annulus with the quickest melting charge starts releasing energy with a rate higher than the annulus with the slowest melting charge. However, in general, the trend of released energy for all configurations are equal. As shown, the concentric case releases the entire energy domain at $F_{O}=0.99$ while the annuli with slowest and quickest melting charge release energy for a longer time $\left(F O=2.98\right.$ and $F_{O}=2.82$, respectively). Therefore, as demonstrated, the annulus with the quickest melting charge compared to other configuration, not only starts releasing energy with a high rate but also it provides thermal energy for a longer time.

\subsection{Charging-discharging cycle (a combined cycle)}

Fig. 18 compares a complete charging-discharging cycle in the concentric and optimum eccentric annuli. Lowering the inner-tube position reduces the melting time due to the enhancement of natural convection in the double-pipe TES, while it adversely affects the discharging process - as conductive heat transfer is the dominant mode of heat transfer during the solidification of the PCM. Therefore, the proposed annulus with the quickest melting charge does not have the quickest combined melting-solidification overall cycle, according to Fig. 18. The concentric configuration with a total Fourier number of 1.66 exhibits the quickest combined melting-solidification cycle. The runner-up with a total Fourier number of 2.92 is the proposed annulus with the quickest melting charge. Finally, the annulus with the slowest melting charge demonstrates the slowest combined melting- 


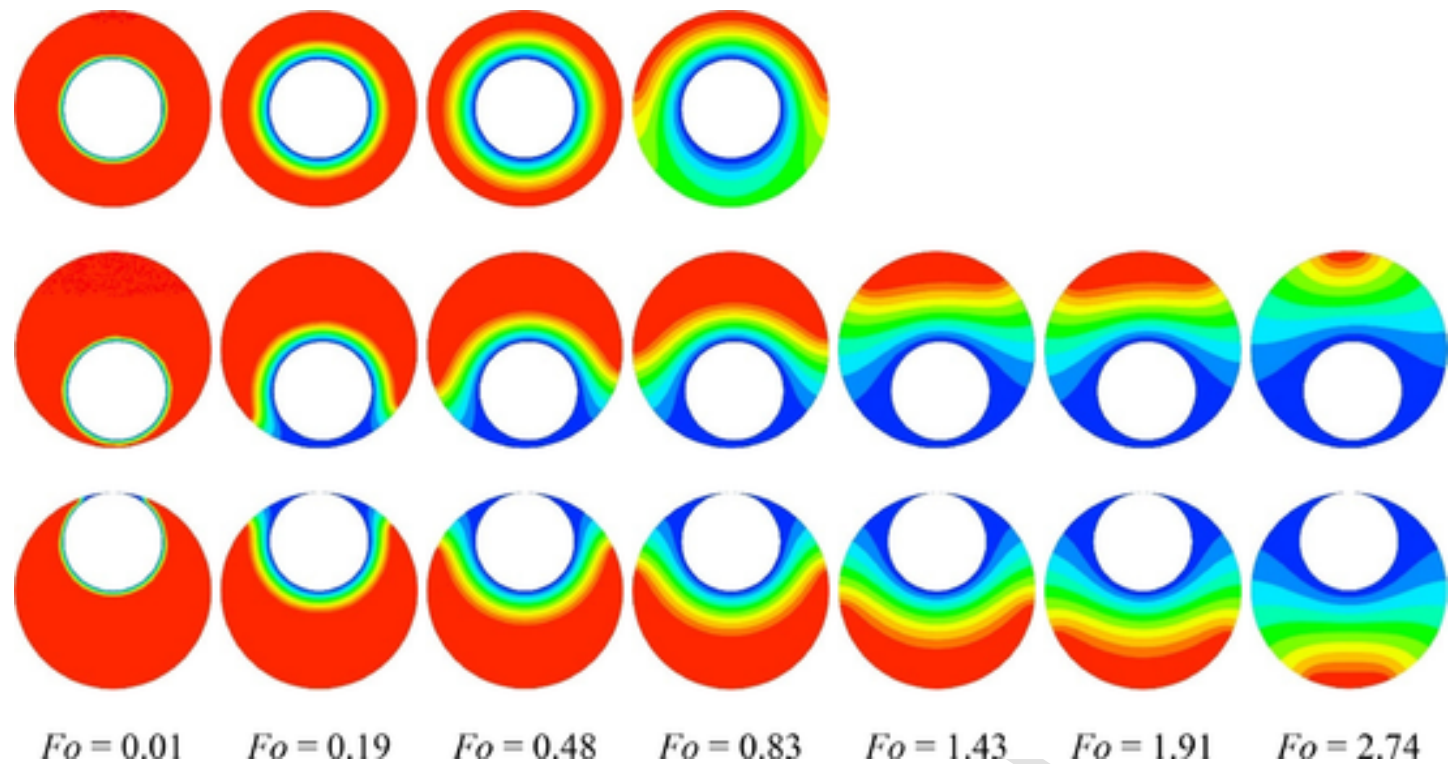

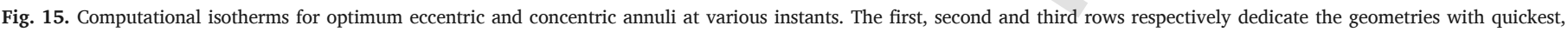
base and slowest melting.

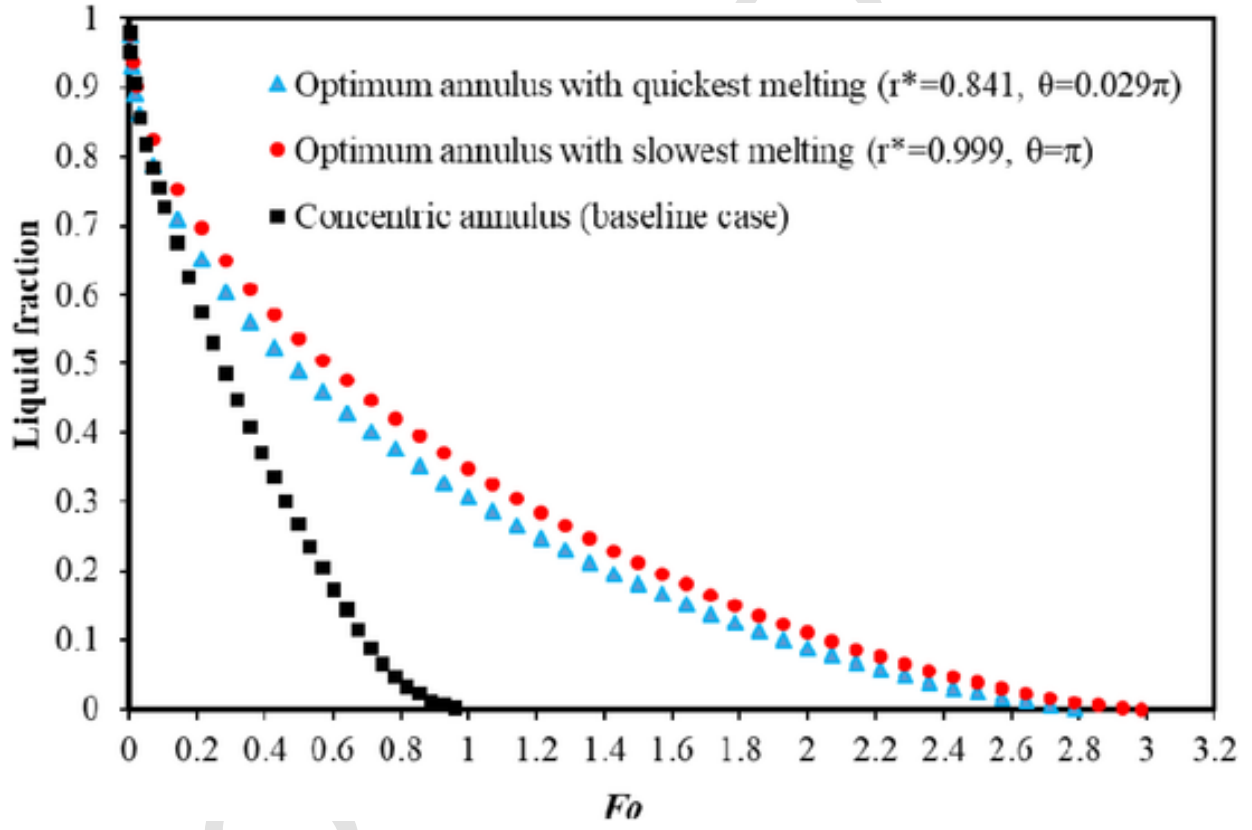

Fig. 16. Comparison of the discharging rates in the concentric and optimum eccentric annulus configurations.

solidification cycle with a total Fourier number of 5.30. The total Fourie number represents the total melting-solidification time, which can be obtained by adding the total charging and total discharging times. These results confirm the findings of Zheng et al. [50], according to whom raising the inner-tube position increases the total time required for a complete melting-solidification cycle.

\subsection{Relative change}

Before continuing with complementary studies and investigating the behaviour of optimum proposed configurations for different PCM materials and shell-to-tube ratios, a relative change has to be defined. Indeed, relative change quantifies the impact of eccentricity on the melting and solidification processes, during the charging (discharging) process. Therefore, a relative change in the charging (discharging) time is defined as:

relative change in the charging (discharging) time

actual charging (discharging) time - baseline charging (discharging) tims baseline charging (discharging) time

The relative changes in the charging and discharging time for TES with shell-to-tube diameter ratio of 2 and filled with n-eicosane are listed in Table 5. The relative changes in charging time for the eccentric annulus with the quickest melting charge is far apart the relative charge the eccentric annulus with the slowest melting charge. However, the relative changes in discharging time for the optimum cases are close to each other. This suggests that the case with the maximum melting charge not only is the best candidate for using in the charging process but also it can be employed as a promising TES that lasts sufficiently long during discharge. 


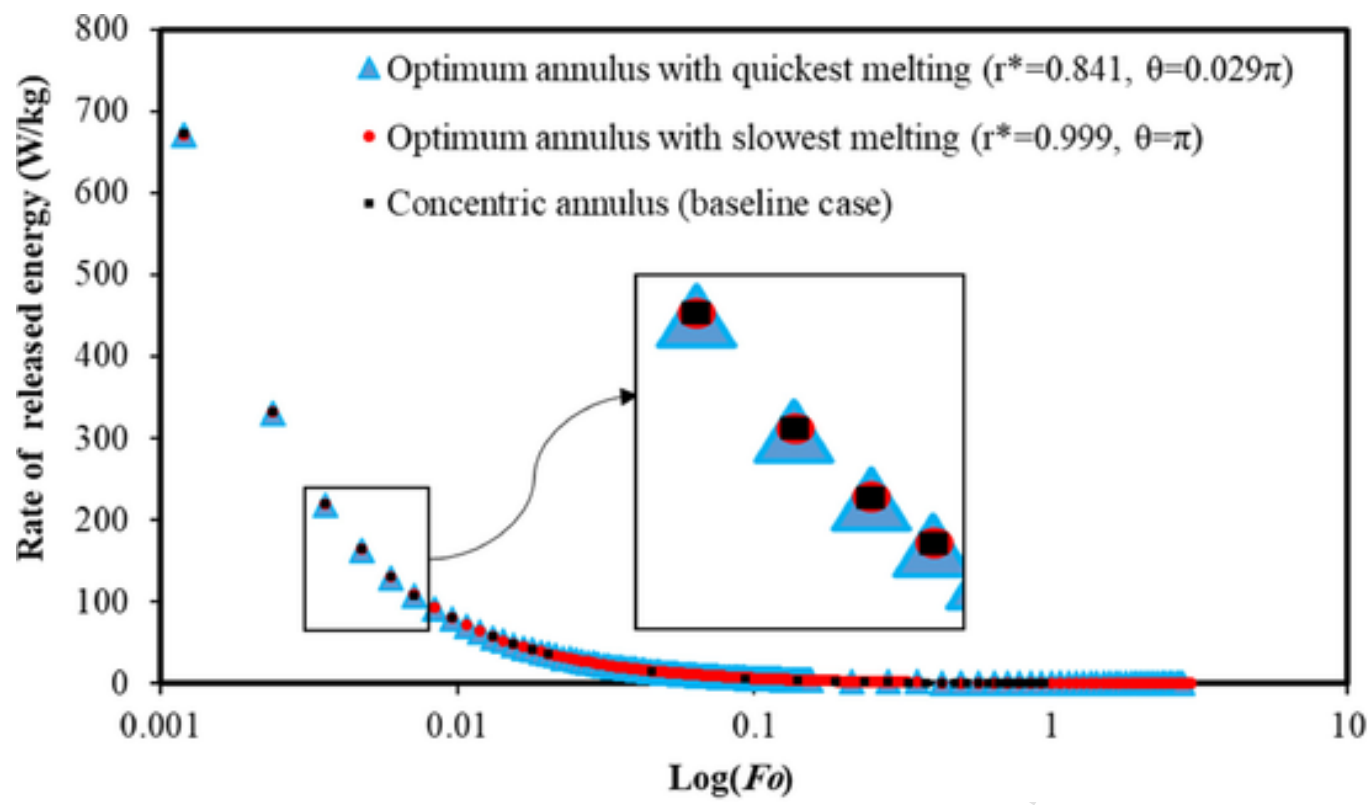

Fig. 17. Comparison of the rate of released energy in the concentric and optimum eccentric annulus configurations.

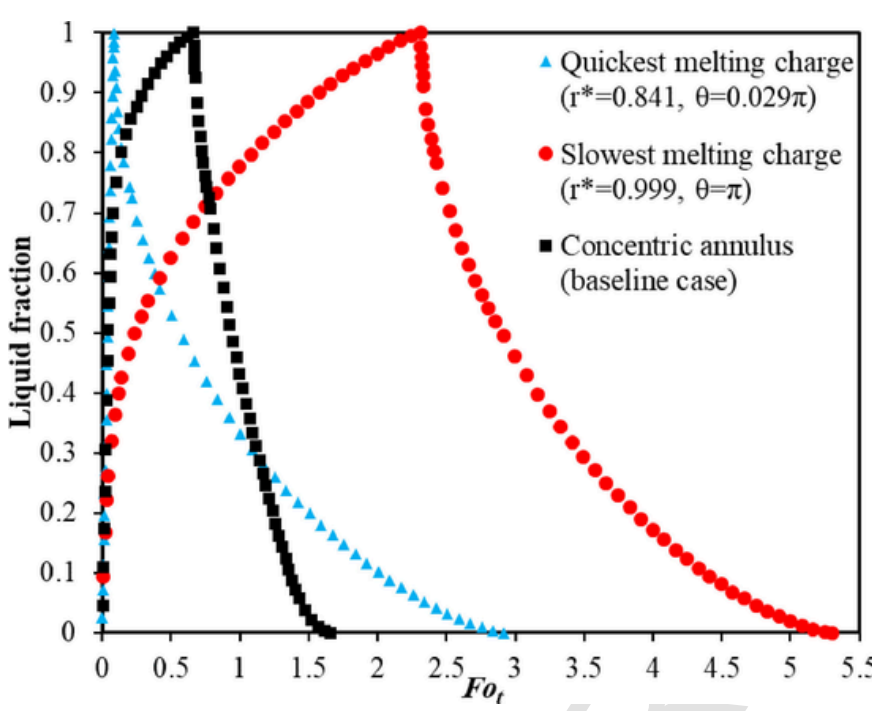

Fig. 18. Comparison of a complete cycle of charging-discharging in the concentric and optimum eccentric annulus configurations.

\subsection{Effect of different PCM materials on proposed optimum configurations}

As a complementary study, the effect of using four different PCMs listed in Table 3: RT31, RT35, RT44HC, and n-eicosane during the melting process in the proposed optimum eccentric annuli and baseline annulus were investigated. Please note that for the sake of brevity and due to the resemblance of result behaviour $s$, the solidification process has not been reported in this complementary study. Therefore, this study requires simulation of 12 cases during the melting process (two optimum eccentric annuli and one concentric annulus for the 4 discussed PCMs). In this study, the inner diameter $(=20 \mathrm{~cm})$ and the shell-to-tube diameter ratio $(=2)$ remained constant for each individual simulation. The initial and boundary conditions of these studies were set as the described settings in Section 2.3.4. Table 6 presents the required full charge Fourier number and the relative change in the charging time of all the aforementioned cases. The baseline annulus and proposed optimum annuli cases present almost similar behaviours
Table 5

Candidate utopian points for TES with shell-to-tube diameter ratio of 2, filled with n-eicosane as the PCM.

\begin{tabular}{llll}
\hline Parameters & Optimum eccentric cases & $\begin{array}{l}\text { Concentric } \\
\text { (base) case }\end{array}$ \\
\hline & $\begin{array}{l}\text { Quickest } \\
\text { melting charge }\end{array}$ & $\begin{array}{l}\text { Slowest } \\
\text { melting charge }\end{array}$ & \\
\hline & 0.841 & 0.999 & 0 \\
\hline $\begin{array}{l}\text { Radial eccentricity }\left(r^{*}\right) \\
\begin{array}{l}\text { Tangential eccentricity } \\
(\theta) \text { [rad] }\end{array}\end{array}$ & $0.029 \pi$ & $\pi$ & 0 \\
$\begin{array}{l}\text { Required Fo to full } \\
\text { charge }\end{array}$ & 0.09 & 2.31 & 0.64 \\
$\begin{array}{l}\text { Required Fo to full } \\
\text { discharge }\end{array}$ & 2.83 & 2.98 & 0.99 \\
$\begin{array}{l}\text { Relative change in } \\
\text { charging time } \\
\text { Relative change in }\end{array}$ & -0.86 & 2.61 & - \\
discharging time & 1.86 & 2.01 & - \\
\hline
\end{tabular}

(almost equal required full charge $F$ o number and relative changes in melting charge) in the presence of RT31 and RT35. While the annuli filled with n-eicosane and RT44HC respectively show the maximum and minimum changes compared to the baseline case. These behaviour s can be justified based on The Rayleigh and Prandtl numbers of these materials. As shown in Table 6, n-eicosane and RT44HC have maximum and minimum Rayleigh number, respectively. Therefore, n-eicosane and RT44HC have the highest and lowest natural convection heat transfer and consequently, they require the highest and lowest charging time, respectively. In addition, since the RT31 and RT35 have nearly equal Rayleigh and Stefan numbers as well as same Prandtl numbers, the quantity of heat transfer (natural convection and conduction) in the annuli containing RT31 is similar to those of using RT35; therefore, they show a comparable trend during the melting process.

The melting trends of these 12 cases are shown in Fig. 19, from which we can see that regardless of the PCM, the annulus with $r^{*}=0.841$ and $\theta=0.029 \pi$ has the quickest melting charge while the annulus with $r^{*}=0.999$ and $\theta=\pi$ has the slowest melting charge.

As shown in Fig. 19, amongst all discussed configurations, the one with n-eicosane and the highest Rayleigh number $\left(3.55 \times 10^{6}\right)$ 
Table 6

Simulation cases for the effect of PCM on Melting.

\begin{tabular}{|c|c|c|c|}
\hline Case & Material & $\begin{array}{l}\text { Required } \\
\text { Fo to full } \\
\text { charge }\end{array}$ & $\begin{array}{l}\text { Relative } \\
\text { change } \\
\text { in } \\
\text { charging } \\
\text { time }\end{array}$ \\
\hline \multirow[t]{4}{*}{ Baseline annulus $\left(r^{*}=0, \theta=0\right)$} & $\begin{array}{l}\text { RT31 } \\
(\mathrm{Ra}=2.75 \times 106 \\
\mathrm{Pr}=25 \\
\text { Ste }=0.247)\end{array}$ & 0.874 & - \\
\hline & $\begin{array}{l}\text { RT35 } \\
(\mathrm{Ra}=2.83 \times 106 \\
\operatorname{Pr}=25 \\
\text { Ste }=0.263)\end{array}$ & 0.847 & \\
\hline & $\begin{array}{l}\text { RT44HC } \\
\left(\mathrm{Ra}=1.77 \times 10^{6},\right. \\
\operatorname{Pr}=33 \\
\text { Ste }=0.168)\end{array}$ & 1.217 & \\
\hline & $\begin{array}{l}\text { N-eicosane } \\
(\mathrm{Ra}=3.55 \times 106 \\
\mathrm{Pr}=63 \\
\text { Ste }=0.209)\end{array}$ & 0.666 & \\
\hline \multirow[t]{4}{*}{$\begin{array}{l}\text { Optimum annulus with the quickest } \\
\text { melting }\left(r^{*}=0.841, \theta=0.029 \pi\right)\end{array}$} & $\begin{array}{l}\text { RT31 } \\
(\mathrm{Ra}=2.75 \times 106 \\
\operatorname{Pr}=25 \\
\text { Ste }=0.247)\end{array}$ & 0.253 & -0.71 \\
\hline & $\begin{array}{l}\text { RT35 } \\
(\mathrm{Ra}=2.83 \times 106 \\
\operatorname{Pr}=25 \\
\text { Ste }=0.263)\end{array}$ & 0.252 & -0.702 \\
\hline & $\begin{array}{l}\text { RT44HC } \\
(\mathrm{Ra}=1.77 \times 106, \\
\operatorname{Pr}=33 \\
\text { Ste }=0.168)\end{array}$ & 0.366 & -0.699 \\
\hline & $\begin{array}{l}\text { N-eicosane } \\
(\mathrm{Ra}=3.55 \times 106 \\
\mathrm{Pr}=63 \\
\text { Ste }=0.209)\end{array}$ & 0.088 & -0.868 \\
\hline \multirow[t]{4}{*}{$\begin{array}{l}\text { Optimum annulus with the slowest } \\
\text { melting }\left(r^{*}=0.999, \theta=\pi\right)\end{array}$} & $\begin{array}{l}\text { RT31 } \\
(\mathrm{Ra}=2.75 \times 106 \\
\mathrm{Pr}=25 \\
\left.\mathrm{~S}^{`} \mathrm{te}=0.247\right)\end{array}$ & 2.690 & 2.078 \\
\hline & $\begin{array}{l}\text { RT35 } \\
(\mathrm{Ra}=2.83 \times 106 \\
\operatorname{Pr}=25 \\
\text { Ste }=0.263)\end{array}$ & 2.621 & 2.094 \\
\hline & $\begin{array}{l}\text { RT44HC } \\
(\mathrm{Ra}=1.77 \times 106, \\
\operatorname{Pr}=33 \\
\text { Ste }=0.168)\end{array}$ & 3.641 & 1.992 \\
\hline & $\begin{array}{l}\text { N-eicosane } \\
(\mathrm{Ra}=3.55 \times 106 \\
\mathrm{Pr}=63 \\
\text { Ste }=0.209)\end{array}$ & 2.317 & 2.479 \\
\hline
\end{tabular}

exhibits the highest melting rate during the charging process, followed by RT35 and RT31 with Rayleigh numbers of $2.83 \times 10^{6}$ and $2.75 \times 10^{6}$, respectively, which exhibit similar melting rates. Finally, RT44HC has the slowest charging time due to its low Rayleigh number $\left(1.77 \times 10^{6}\right)$. These results confirm the findings of Zheng et al. [50] that increasing the Rayleigh number leads to an increase in both melting and solidification times.

Fig. 20 compares the energy storing rate per unit mass of PCM for different PCMs used in the annulus with the quickest melting charge. The annulus filled with n-eicosane stores energy with the highest rate and in a shorter time. This is followed by the annulus filled with RT44HC, while the lowest energy storage rate is observed in the annuli filled with RT35 and RT31. However, the longest storage time is achieved for the annulus filled with RT44HC.

\subsection{Effect of the shell-to-tube diameter ratio on the proposed optimum configurations}

As another complimentary study, the dependency of the proposed optimisation results on the diameter ratio of the annuli is investigated during the melting process. Again, for the sake of brevity and due to the resemblance of result behaviour $\mathrm{s}$, the solidification process has not been reported in this complementary study. Three distinctive shell-to-tube diameter ratios (1.5, 2 and 2.5) where for each diameter ratio, the melting process of the proposed optimum annuli (the ones with the quickest melting and slowest melting charge) along the baseline in the presence of n-eicosane were investigated. Moreover, for investigating the independency of the optimum results, two additional control cases were considered to examine the influence of the radial eccentricity on the charging time. These additional control cases are defined by adjusting the position of the inner tube $10 \%$ above and $10 \%$ below the optimum points. It is worth noting that, in the optimum slowest charging case, since the inner tube is located on the uppermost part of the shell (outer tube), only one additional case (a case with $10 \%$ below the optimum point of annuls) is investigated. Therefore, in this study, a total of 15 different annuli with the same inner diameter $(=20 \mathrm{~cm})$ filled with n-eicosane PCM are investigated, as listed in Table 7. This table reports the required time and Fourier number (dimensional and non-dimensional time values) for a complete charge of the individual annulus.

Figs. 21 and 22 show the independency of the optimisation results for various diameter ratios (1.5, 2, and 2.5) and radial eccentricity control cases (10\% above and $10 \%$ below the optimum points) during the melting process. As shown, the optimisation results are independent of the diameter ratio. With all diameter ratios tested in this paper $(1.5,2$, and 2.5), the optimum annulus with $r^{*}=0.841$ and $\theta=0.029 \pi$ outperforms other configurations, while the annulus with $r^{*}=0.999$ and $\theta=\pi$ shows the longest melting time among the proposed annuli (please consult Figs. 18 and 19, and Table 7). The natural convection is enhanced with increasing radial eccentricity towards the optimum point. Therefore, the performance of the control case with radial eccentricity $10 \%$ above the optimum point is nearly similar to that of $10 \%$ below the optimum point. However, the differences between the performance of the optimum annuli and the control cases are marginal in all diameter ratios tested in this paper. Especially, the difference between the melting time of annulus with the quickest melting charge and control cases (where the inner tube is positioned 10\% above and below the position of the inner tube of the annulus with the quickest melting charge) is negligible, but still proposed optimum configurations show better performances (see Table 7).

\subsection{Utilisation of the optimum eccentricity in commercial TES applications}

In previous sections, the annulus with the quickest-melting optimum eccentricity $\left(r^{*}=0.841, \theta=0.029 \pi\right)$ was identified as the configuration that exhibits the fastest charging time (i.e., the highest heat-transfer rate as shown in Fig. 11), while releasing thermal energy at a significantly lower rate as compared to the baseline concentric case (2.8 times slower, as shown in Table 5). Due to its dynamic characteristics, a double-pipe heat exchanger with this specific eccentricity is a promising candidate for use as a passive thermal storage system in nearly zero-emission buildings. Yet, inner-pipe(s) eccentricity optimisation can be performed for more complex heat-exchanger configurations, for which the findings of this article can provide guidance.

Shell and multi-tube thermal energy stores are an alternative solution to increase the heat-transfer rate between the PCM and heat-transfer fluid: increasing the number of tubes in the shell enhances the transfer area, and hence the melting rate $[61,62]$. However, a higher number of inner pipes leads to an increase in the pressure drop in 


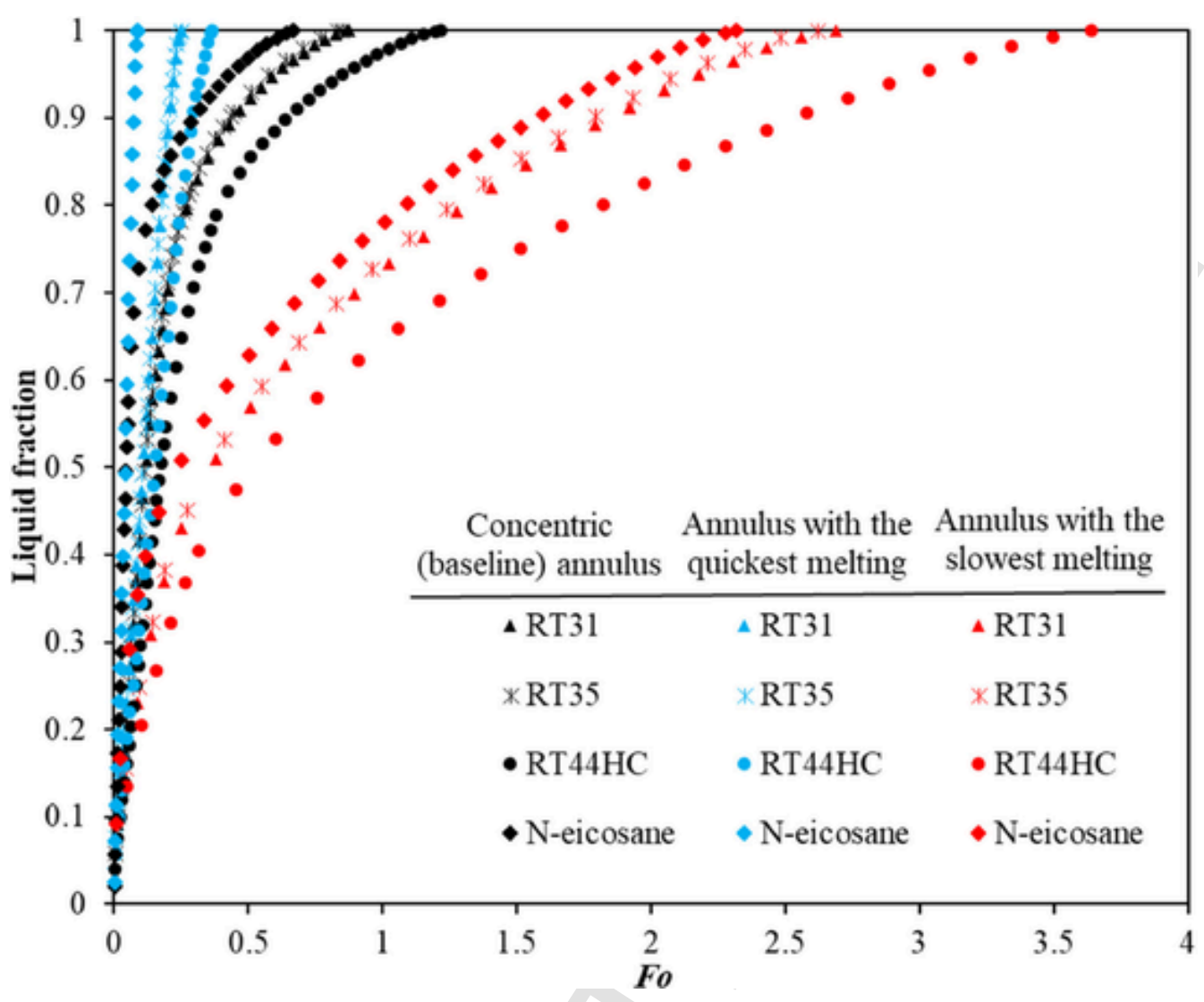

Fig. 19. Effect of the different PCMs on the melting process.

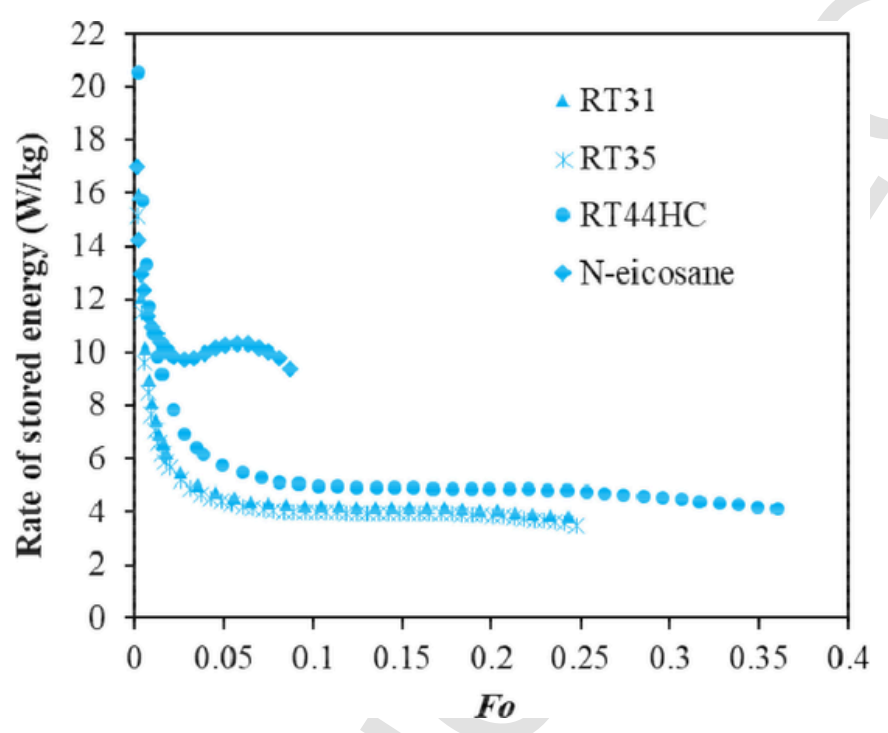

Fig. 20. Comparison of the rate of stored energy for different PCM filled in the annulus with the quickest melting charge.

the HTF. The main challenge in designing multi-tube TES is to determine the optimum arrangement of the tubes in the shell. Eisapour et al. [61] investigated different arrangements of four tubes in the shell. They found that arrangement shown in Fig. 23(a) - in which the tubes are assembled together and in the lowermost part of the shell - exhibit higher charging performance. These findings are aligned with those of the presented study.

The shell and double-pipe TES, shown in Fig. 23(b), is another well-known solution for solar-based building thermal management, inside which both cold (for cooling down or discharging the PCM) and hot (for heating up or charging the PCM) HTF streams circulate. Such a thermal storage system can be employed to even out the mismatch between the energy supply and demand. In applications such as solar domestic hot water (SDHW) systems, the TES can be charged and discharged at irregular intervals, due to the mismatch between the domestic hot water demand and the inherently intermittent solar irradiation [63]. The shell and double-pipe TES shown in Fig. 23(b) can be charged and discharged at either separate time intervals, or simultaneously. During simultaneous charging and discharging of the TES, both a fast charge and discharge are desired. The findings of the current study provide valuable guidance for achieving this aim with the proposed design. In the arrangement shown in Fig. 23(b), the heat-transfer rate from the hot HTF towards the PCM is enhanced by positioning the heating pipe at the quickest-melting optimum eccentricity (as determined in the current study, see Fig. 11), while the cooling pipe is placed at the centre of the shell (i.e., at the concentric position, identified as the fastest discharge configuration as shown in Fig. 16) to increase the discharge rate. However, it is worth noting that this very configuration is not optimal and would require a dedicated optimisation to determine the absolute optimum positions of both the hot and cold tubes.

\section{Conclusions}

The present study has considered optimising the performance of a TES system, in which a phase-change material (PCM) is placed in the eccentric annulus of a horizontal double-pipe heat exchanger, by varying the annulus radial and tangential eccentricities of this configuration. N-eicosane is used here as the PCM. Response-surface optimisation methods were used together with CFD simulations to determine the optimal design variables (i.e., the radial and tangential 
Table 7

Annuli used for the study of the effect of the shell-to-tube diameter ratio.

\begin{tabular}{|c|c|c|c|c|}
\hline Case & Eccentricity & $\begin{array}{l}\text { Diameter } \\
\text { ratio }\end{array}$ & $\begin{array}{l}\text { Required } \\
\text { time to } \\
\text { full } \\
\text { charge } \\
\text { (min) }\end{array}$ & $\begin{array}{l}\text { Required } \\
\text { Fo to full } \\
\text { charge }\end{array}$ \\
\hline \multirow[t]{9}{*}{ Quick melting charge } & $\begin{array}{l}10 \% \text { above } \\
\text { the } \\
\text { quickest ( } \\
r^{*}=0.757 \\
\theta=0.029 \pi)\end{array}$ & 1.5 & 3.4 & 0.162 \\
\hline & & 2 & 7.9 & 0.094 \\
\hline & & 2.5 & 12.6 & 0.067 \\
\hline & $\begin{array}{l}\text { Quickest } \\
\text { melting } \\
\text { charge ( } \\
r^{*}=0.841 \\
\theta=0.029 \pi)\end{array}$ & 1.5 & 3.1 & 0.148 \\
\hline & & 2 & 7.4 & 0.088 \\
\hline & & 2.5 & 12.3 & 0.065 \\
\hline & $\begin{array}{l}10 \% \text { below } \\
\text { the } \\
\text { quickest ( } \\
r^{*}=0.925 \\
\theta=0.029 \pi)\end{array}$ & 1.5 & 3.5 & 0.167 \\
\hline & & 2 & 7.9 & 0.094 \\
\hline & & 2.5 & 12.6 & 0.067 \\
\hline \multirow[t]{6}{*}{ Slow melting charge } & $\begin{array}{l}\text { Slowest } \\
\text { melting } \\
\text { charge ( } \\
r^{*}=0.999 \\
\theta=\pi \text { ) }\end{array}$ & 1.5 & 50.8 & 2.422 \\
\hline & & 2 & 194.4 & 2.317 \\
\hline & & 2.5 & 436.7 & 2.313 \\
\hline & $\begin{array}{l}10 \% \text { below } \\
\text { the slowest } \\
\left(r^{*}=0.899\right. \\
\theta=\pi)\end{array}$ & 1.5 & 46.3 & 2.207 \\
\hline & & 2 & 175.4 & 2.091 \\
\hline & & 2.5 & 392.5 & 2.079 \\
\hline
\end{tabular}

eccentricities), so as to maximize or minimize the TES charging time, defined as the time required to melt the whole PCM region. Two-dimensional transient thermofluid simulations of the buoyancy-driven melting of the PCM were performed using the enthalpy-porosity method.

The optimisation study demonstrated that both radial and tangential eccentricities influence the performance of the TES system, although the optimisation is more sensitive to the tangential than the radial eccentricity. Eccentric annuli with higher radial and tangential eccentricities drastically reduce the charging ability of the TES, due to the suppression of the natural convection in the annulus. However, the charging time of the proposed system significantly drops by placing the inner tube at higher radial and lower tangential eccentricities. In the presence of n-eicosane the charging time of the most effective, i.e., the quickest, eccentric-annulus configuration (with $r^{*}=0.841$ and $\theta=0.029 \pi$ ), is 7.1 times faster than the baseline concentric case, while the slowest configuration $\left(r^{*}=0.999\right.$ and $\left.\theta=\pi\right)$ melts 3.6 times more slowly than the baseline.

During charging of the TES system, three distinct zones are observed, each dominated by a specific heat-transfer mechanism: a buoyancy-driven, convection-dominant zone, a mixed weak convection and conduction zone, and a diffusion-dominated zone. The convection-dominant zone plays a significant role in the melting process as the highest heat-flow rates are achieved in this region. The quickest configuration is, in fact, the geometrical arrangement that favours this heat-transfer mode, with most of the PCM region available for the development of convection cells.
During the discharge phase, the heat transfer is dominated by thermal diffusion, while the convective effects can be neglected. Due to a larger phase-change front area (i.e., the interface area between the solid and molten PCM), the solidification process is considerably faster ( $F o=0.99$ for n-eicosane) in the baseline case (i.e., the concentric annulus configuration) in comparison with the two optimum cases (i.e., with the inner cylinder placed in the uppermost and lowermost positions), for which the solidification of the PCM lasts approximately three times longer (e.g., for n-eicosane $F o=2.83$ and $F_{O}=2.98$, respectively). Although not ideal for electricity storage purposes, a fast-charging and slow-discharging thermal store is well suited for use in the building sector to help reduce the air-conditioning energy consumption. However, it is found that the quickest complete melting-solidification cycle is achieved with a concentric inner-outer-pipes configuration $(F o=1.66)$, with an overall cycle duration 1.8 times shorter than that with the quickest-melting optimum eccentricity $(F o=2.99)$ and 3.2 times shorter than that with the slowest-melting optimum $(F o=5.30)$.

Complementary studies were performed to examine the dependency of the optimisation results on the PCM type and shell-to-tube diameter ratio. Simulations using four different PCMs (RT31, RT35, RT44HC, and n-eicosane) were performed and have shown that the optimum eccentric position enhances the charging and discharging processes for all investigated PCMs, while the n-eicosane-filled TES stores energy in a shorter time compared to those filled with the other PCMs considered in this paper. In addition, results obtained with three distinct diameter ratios (1.5, $2,2.5)$ prove that the latter has no significant impact on the optimisation results.

\section{Declaration of Competing Interests}

\section{None}

\section{Acknowledgements}

The authors gratefully acknowledge the CHPC in the Republic of South Africa for providing the computing facilities and the software used the simulations. This work was supported by the UK Engineering and Physical Sciences Research Council (EPSRC) [grant numbers EP/P004709/1, EP/ R045518/1, EP/S032622/1]. Data supporting this publication can be obtained on request from cep-lab@imperial.ac.uk.

Appendix A. . Relationship between energy storage rate and liquid fraction in PCM-based TES

The energy storage rate at a given instance is:

$\eta=\frac{Q_{\text {stored }}}{Q_{\max }}$

where $Q_{\text {stored }}$ is the amount of thermal energy stored in a TES system at each instance and $Q_{\max }$ is the maximum amount of thermal energy that can be stored in the same TES unit.

If the temperature difference between the initial state and the saturation temperature (two phase temperature) is small, then the liquid fraction is equal or almost equal to the energy storage rate. To prove this fact, consider the following two cases.

Case 1: No difference between the initial temperature and saturation temperature

Imagine a charging TES when initially the solid PCM is at the melting temperature $\left(T_{\mathrm{i}}=T_{\mathrm{m}}\right)$. Then, $Q_{\text {stored }}$ at any time-instance is equal to the latent heat of fusion and consequently, the energy storage rate from Equation (A.1) can be written as:

$\eta=\frac{m_{1} L}{m_{\mathrm{t}} L}=f$ 


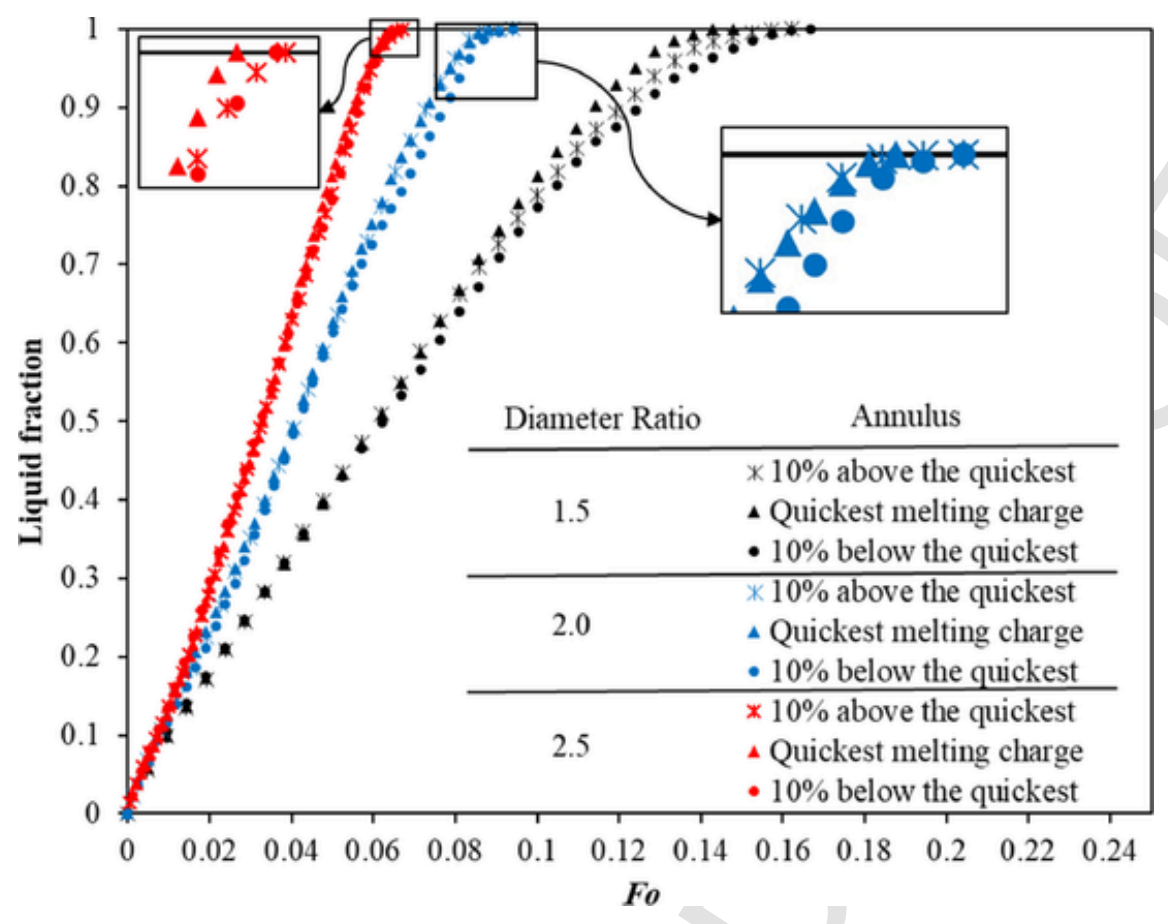

Fig. 21. Effect of diameter ratio and radial eccentricity for the quickest melting charge on the annuli filled with n-eicosane.

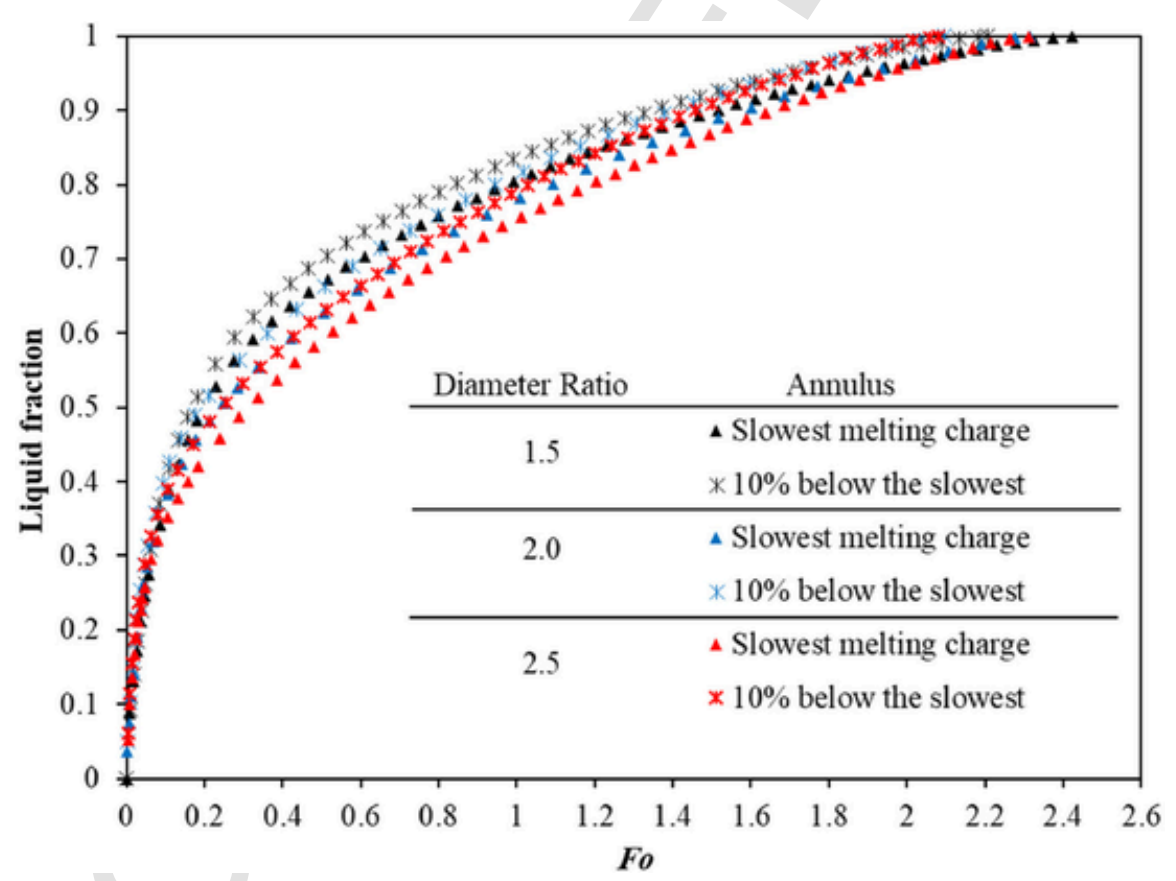

Fig. 22. Effect of diameter ratio and radial eccentricity for the slowest melting charge on the annuli filled with n-eicosane.

where $m_{1}$ and $m_{\mathrm{t}}$ are the mass of liquid PCM at that instance and the total mass of PCM, respectively. $L$ is the latent heat of fusion and $f$ is liquid fraction which is defined as the ratio of the mass of liquid to the total mass.

Therefore, the energy storage rate is equal to the liquid fraction in this case.

Case 2: Slight difference between the initial temperature and saturation temperature

Imagine a charging TES when initially the solid PCM is slightly subcooled. In this case, the amount of stored energy in the system at any instance is the summation of sensible and latent heat transferred to the TES system. Therefore, Equation (A.1) can be written as:

$\eta=\frac{m_{1} L+Q_{\mathrm{se}}}{m_{\mathrm{t}} L+Q_{\mathrm{se}}}$

where $Q_{\mathrm{se}}$ is the amount of sensible heat required to reach solid PCM from initial subcooled state to the melting point which can be calculated from:

$Q_{\mathrm{se}}=m_{\mathrm{t}}\left\{\left[h_{\mathrm{i}}+c_{\mathrm{p}}\left(T_{\mathrm{m}}-T_{\mathrm{i}}\right)\right]-h_{\mathrm{i}}\right\}$

where $h_{\text {initial }}$ is enthalpy at the initial temperature and $c_{\mathrm{p}}$ is specific heat. By considering the PCM is subcooled, e.g., at $1 \mathrm{~K}$ (which is 


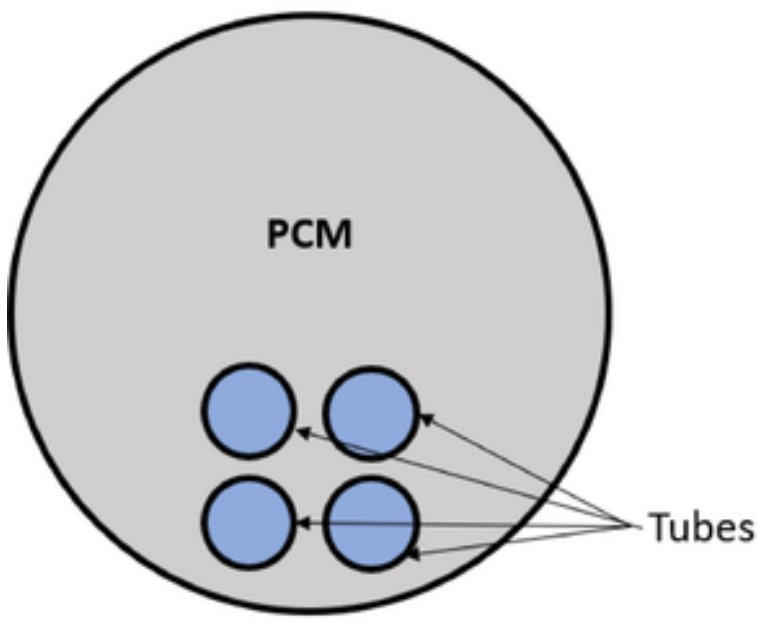

(a)

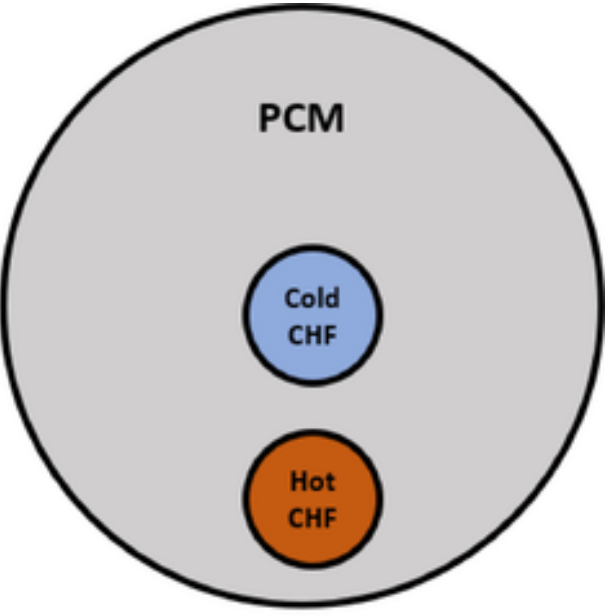

(b)

Fig. 23. Schematic of: (a) shell and multi-tube TES with four tubes; and (b) shell and double-pipe TES with simultaneous charging and discharging.

the case of this study). Then $T_{\mathrm{m}}-T_{\mathrm{i}}=1$ and the energy storage rate can be formulated as follows:

$\eta=\frac{f L+c_{\mathrm{p}}}{L+c_{\mathrm{p}}}$

By simplifying Equation A.5, then the energy storage rate is:

$\eta=\frac{f}{1+\frac{c_{\mathrm{p}}}{L}}+\frac{\frac{c_{\mathrm{p}}}{L}}{1+\frac{c_{\mathrm{p}}}{L}}$

Since the specific heat $\left(c_{\mathrm{p}}\right)$ is much smaller than the latent heat of fusion $(L)$ then $\frac{c_{\mathrm{p}}}{L}$ is negligible (E.g. in this study this ratio is in the order $10^{-2}$, please see Table 3), Therefore the energy storage rate, $\eta$ can be approximated by the liquid fraction $(\eta \sim f)$.

\section{References}

[1] T. Nuytten, B. Claessens, K. Paredis, J. Van Bael, D. Six, Flexibility of a combined heat and power system with thermal energy storage for district heating, Appl. Energy 104 (2013) 583-591, doi:10.1016/j.apenergy.2012.11.029.

[2] M. Dardir, K. Panchabikesan, F. Haghighat, M. El Mankibi, Y. Yuan, Opportunities and challenges of PCM-to-air heat exchangers (PAHXs) for building free cooling applications-A comprehensive review, J. Energy Storage 22 (2019) 157-175, doi:10.1016/J.EST.2019.02.011.

[3] F. Agyenim, N. Hewitt, P. Eames, M. Smyth, A review of materials, heat transfer and phase change problem formulation for latent heat thermal energy storage systems (LHTESS), Renew. Sustain. Energy Rev. 14 (2010) 615-628, doi:10.1016/j.rser.2009.10.015.

[4] M. Medrano, M.O. Yilmaz, M. Nogués, I. Martorell, J. Roca, L.F. Cabeza, Experimental evaluation of commercial heat exchangers for use as PCM thermal storage systems, Appl. Energy 86 (2009) 2047-2055, doi:10.1016/ j.apenergy.2009.01.014.

[5] S. Jegadheeswaran, S.D. Pohekar, Performance enhancement in latent heat thermal storage system: a review, Renew. Sustain. Energy Rev. 13 (2009) 2225-2244, doi:10.1016/j.rser.2009.06.024.
[6] S. Seddegh, X. Wang, A.D. Henderson, Z. Xing, Solar domestic hot water systems using latent heat energy storage medium: a review, Renew. Sustain. Energy Reviews 49 (2015) 517-533, doi:10.1016/j.rser.2015.04.147.

[7] A. Gupta, R. Mathie, C. Markides, An experimental and computational investi gation of a thermal storage system based on a phase change material: heat transfer and performance characterization, Comput. Thermal Sci (2014) 6, doi:10.1615/.2014011117.

[8] S.M. Hasnain, Review on sustainable thermal energy storage technologies, Part I: heat storage materials and techniques, Energy Conver. Manag. 39 (1998) 1127-1138, doi:10.1016/s0196-8904(98)00025-9.

[9] L. Liu, D. Su, Y. Tang, G. Fang, Thermal conductivity enhancement of phase change materials for thermal energy storage: a review, Renew. Sustain. Energy Rev. 62 (2016) 305-317, doi:10.1016/j.rser.2016.04.057.

[10] E.B.S. Mettawee, G.M.R. Assassa, Thermal conductivity enhancement in a latent heat storage system, Solar Energy 81 (2007) 839-845, doi:10.1016/ j.solener.2006.11.009.

[11] F.I. Doshmanziari, M.R. Kadivar, M. Yaghoubi, D. Jalali-Vahid, M.A. Arvinfar, Experimental and numerical study of turbulent fluid flow and heat transfer of Al2O3/Water Nanofluid in a Spiral-Coil Tube, Heat Transfer Eng. 38 (2017) 611-626, doi:10.1080/01457632.2016.1200380.

[12] F.I. Doshmanziari, A.E. Zohir, H.R. Kharvani, D. Jalali-Vahid, M.R. Kadivar, Characteristics of heat transfer and flow of $\mathrm{Al} 2 \mathrm{O} 3$ /water nanofluid in a spiral-coil tube for turbulent pulsating flow, Heat Mass Transfer 52 (2016) 1305-1320, doi:10.1007/s00231-015-1651-y.

[13] S. Kakaç, A.E. Bergles, F. Mayinger, H. Yüncü, Heat transfer enhancement of heat exchangers, Springer Sci. Bus. Media (2013).

[14] J. Zhang, X. Zhu, M.E. Mondejar, F. Haglind, A review of heat transfer enhancement techniques in plate heat exchangers, Renew. Sustain. Energy Rev. 101 (2019) 305-328, doi:10.1016/j.rser.2018.11.017.

[15] H. Yin, X. Gao, J. Ding, Z. Zhang, Experimental research on heat transfer mechanism of heat sink with composite phase change materials, Energy Conver. Manag. 49 (2008) 1740-1746, doi:10.1016/j.enconman.2007.10.022.

[16] O.K. Yagci, M. Avci, O. Aydin, Melting and solidification of pcm in a tube-in-shell unit: effect of fin edge lengths' ratio, J. Energy Storage 24 (2019), doi:10.1016/J.EST.2019.100802 100802.

[17] A. Jamekhorshid, S.M. Sadrameli, M. Farid, A review of microencapsulation methods of phase change materials (PCMs) as a thermal energy storage (TES) medium, Renew. Sustain. Energy Rev. 31 (2014) 531-542, doi:10.1016/ j.rser.2013.12.033.

[18] M.N.A. Hawlader, M.S. Uddin, M.M. Khin, Microencapsulated PCM thermal-energy storage system, Appl. Energy 74 (2003) 195-202, doi:10.1016/ S0306-2619(02)00146-0.

[19] M. Esapour, A. Hamzehnezhad, A.A. Rabienataj Darzi, M. Jourabian, Melting and solidification of PCM embedded in porous metal foam in horizontal multi- 
tube heat storage system, Energy Conver. Manag. 171 (2018) 398-410, doi:10.1016/j.enconman.2018.05.086.

[20] Z. Deng, X. Liu, C. Zhang, Y. Huang, Y. Chen, Melting behaviors of PCM in porous metal foam characterized by fractal geometry, Int. J. Heat Mass Transf. 113 (2017) 1031-1042, doi:10.1016/j.ijheatmasstransfer.2017.05.126.

[21] L. Qiu, Y. Ouyang, Y. Feng, X. Zhang, Review on micro/nano phase change materials for solar thermal applications, Renew. Energy 140 (2019) 513-538, doi:10.1016/j.renene.2019.03.088.

[22] M. Al-Jethelah, S.H. Tasnim, S. Mahmud, A. Dutta, Nano-PCM filled energy storage system for solar-thermal applications, Renew. Energy 126 (2018) 137-155, doi:10.1016/j.renene.2018.02.119.

[23] M. Gorzin, M.J. Hosseini, M. Rahimi, R. Bahrampoury, Nano-enhancement of phase change material in a shell and multi-PCM-tube heat exchanger, J. Energy Storage 22 (2019) 88-97, doi:10.1016/J.EST.2018.12.023.

[24] M. Bashar, K. Siddiqui, Experimental investigation of transient melting and heat transfer behavior of nanoparticle-enriched PCM in a rectangular enclosure, J. Energy Storage 18 (2018) 485-497, doi:10.1016/J.EST.2018.06.006.

[25] W. Li, D. Zhang, T. Jing, M. Gao, P. Liu, G. He, F. Qin, Nano-encapsulated phase change material slurry (Nano-PCMS) saturated in metal foam: a new stable and efficient strategy for passive thermal management, Energy 165 (2018) 743-751, doi:10.1016/j.energy.2018.09.147.

[26] J.M. Mahdi, E.C. Nsofor, Solidification enhancement in a triplex-tube latent heat energy storage system using nanoparticles-metal foam combination, Energy 126 (2017) 501-512, doi:10.1016/j.energy.2017.03.060.

[27] J. Fukai, Y. Hamada, Y. Morozumi, O. Miyatake, Improvement of thermal characteristics of latent heat thermal energy storage units using carbon-fiber brushes: experiments and modeling, Int. J. Heat Mass Transf. 46 (2003) 4513-4525, doi:10.1016/S0017-9310(03)00290-4.

[28] K. Panchabikesan, M.V. Swami, V. Ramalingam, F. Haghighat, Influence of PCM thermal conductivity and HTF velocity during solidification of PCM through the free cooling concept - A parametric study, J. Energy Storage 21 (2019) 48-57, doi:10.1016/J.EST.2018.11.005.

[29] L. Kalapala, J.K. Devanuri, Influence of operational and design parameters on the performance of a PCM based heat exchanger for thermal energy storage - A review, J. Energy Storage 20 (2018) 497-519, doi:10.1016/J.EST.2018.10.024

[30] D.B. Khillarkar, Z.X. Gong, A.S. Mujumdar, Melting of a phase change material in concentric horizontal annuli of arbitrary cross-section, Appl. Therm. Eng. 20 (2000) 893-912, doi:10.1016/S1359-4311(99)00058-7.

[31] B. Zivkovic, I. Fujii, an analysis of isothermal phase change of phase change, Solar Energy 70 (2001) 51-61, doi:10.1016/S0038-092X(00)00112-2.

[32] N.R. Vyshak, G. Jilani, Numerical analysis of latent heat thermal energy storage system, Energy Conver. Manag. 48 (2007) 2161-2168, doi:10.1016/ j.enconman.2006.12.013.

[33] R.E. Murray, D. Groulx, Experimental study of the phase change and energy characteristics inside a cylindrical latent heat energy storage system: part 1 consecutive charging and discharging, Renew. Energy 62 (2014) 571-581, doi:10.1016/j.renene.2013.08.007.

[34] S. Seddegh, X. Wang, A.D. Henderson, Numerical investigation of heat transfer mechanism in a vertical shell and tube latent heat energy storage system, Appl. Therm. Eng. 87 (2015) 698-706, doi:10.1016/j.applthermaleng.2015.05.067.

[35] S. Seddegh, X. Wang, M.M. Joybari, F. Haghighat, Investigation of the effect of geometric and operating parameters on thermal behavior of vertical shell-and-tube latent heat energy storage systems, Energy 137 (2017) 69-82, doi:10.1016/j.energy.2017.07.014.

[36] S. Seddegh, M.M. Joybari, X. Wang, F. Haghighat, Experimental and numerical characterization of natural convection in a vertical shell-and-tube latent thermal energy storage system, Sustain. Citie. Soc. 35 (2017) 13-24, doi:10.1016/ j.scs.2017.07.024.

[37] N. Kousha, M.J. Hosseini, M.R. Aligoodarz, R. Pakrouh, R. Bahrampoury, Effect of inclination angle on the performance of a shell and tube heat storage unit-An experimental study, Appl. Therm. Eng 112 (2017) 1497-1509.

[38] S. Seddegh, X. Wang, A.D. Henderson, A comparative study of thermal behaviour of a horizontal and vertical shell-and-tube energy storage using phase change materials, Appl. Therm. Eng. 93 (2016) 348-358.
[39] M.J. Hosseini, M. Rahimi, R. Bahrampoury, Experimental and computational evolution of a shell and tube heat exchanger as a PCM thermal storage system Int. Commun. Heat Mass Transf. 50 (2014) 128-136, doi:10.1016/ j.icheatmasstransfer.2013.11.008.

[40] F. Rösler, D. Brüggemann, Shell-and-tube type latent heat thermal energy stor age:, numerical analysis and comparison with experiments, Heat Mass Transf. 47 (2011) 1027-1033, doi:10.1007/s00231-011-0866-9.

[41] M. Avci, M.Y. Yazici, Experimental study of thermal energy storage characteristics of a paraffin in a horizontal tube-in-shell storage unit, Energy Conver. Manag. 73 (2013) 271-277, doi:10.1016/j.enconman.2013.04.030.

[42] W.-W. Wang, K. Zhang, L.-B. Wang, Y.-L. He, Numerical study of the heat charging and discharging characteristics of a shell-and-tube phase change heat storage unit, Appl. Therm. Eng. 58 (2013) 542-553, doi:10.1016/ j.applthermaleng.2013.04.063.

[43] Y. Zhang, A. Faghri, Analysis of freezing in an eccentric annulus, J. Sol. Energy Eng. 119 (2008) 237, doi:10.1115/1.2888025.

[44] R. Dutta, A. Atta, T.K. Dutta, Experimental and numerical study of heat transfer in horizontal concentric annulus containing phase change material, Canad. J. Chem. Eng. 86 (2008) 700-710, doi:10.1002/cjce.20075.

[45] N.S. Dhaidan, J.M. Khodadadi, T.A. Al-Hattab, S.M. Al-Mashat, Experimental and numerical investigation of melting of NePCM inside an annular container under a constant heat flux including the effect of eccentricity, Int. J. Heat Mass Transf. 67 (2013) 455-468, doi:10.1016/j.ijheatmasstransfer.2013.08.002.

[46] A.R. Darzi, M. Farhadi, K. Sedighi, Numerical study of melting inside concentric and eccentric horizontal annulus, Appl. Math. Model 36 (2012) 4080-4086, doi:10.1016/j.apm.2011.11.033.

[47] M.Y. Yazici, M. Avci, O. Aydin, M. Akgun, On the effect of eccentricity of a horizontal tube-in-shell storage unit on solidification of a PCM, Appl. Therm. Eng. 64 (2014) 1-9, doi:10.1016/j.applthermaleng.2013.12.005.

[48] M. Yusuf Yazici, M. Avci, O. Aydin, M. Akgun, Effect of eccentricity on melting behavior of paraffin in a horizontal tube-in-shell storage unit: an experimental study, Solar Energy 101 (2014) 291-298, doi:10.1016/j.solener.2014.01.007.

[49] Y. Pahamli, M.J. Hosseini, A.A. Ranjbar, R. Bahrampoury, Analysis of the effect of eccentricity and operational parameters in PCM-filled single-pass shell and tube heat exchangers, Renew. Energy 97 (2016) 344-357, doi:10.1016/ j.renene.2016.05.090.

[50] Z.J. Zheng, Y. Xu, M.J. Li, Eccentricity optimization of a horizontal shell-and-tube latent-heat thermal energy storage unit based on melting and melting-solidifying performance, Appl. Energy 220 (2018) 447-454, doi:10.1016/j.apenergy.2018.03.126.

[51] A.D. Brent, V.R. Voller, K.J. Reid, Enthalpy-porosity technique for modeling convection-diffusion phase change: application to the melting of a pure metal, Numer. Heat Transf. 13 (1988) 297-318, doi:10.1080/10407788808913615.

[52] V.R. Voller, C. Prakash, A fixed grid numerical modelling methodology for convection-diffusion mushy region phase-change problems, Int. J. Heat Mass Transf. 30 (1987) 1709-1719, doi:10.1016/0017-9310(87)90317-6.

[53] V.R. Voller, C.R. Swaminathan, B.G. Thomas, Fixed grid techniques for phase change problems: a review, Int. J. Numer. Methods Eng. 30 (1990) 875-898, doi:10.1002/nme.1620300419.

[54] M.M. Joybari, F. Haghighat, S. Seddegh, Natural convection characterization during melting of phase change materials: development of a simplified front tracking method, Solar Energy 158 (2017) 711-720, doi:10.1016/ j.solener.2017.10.031

[55] ANSYS Design Exploration User's Guide Release 18.1, ANSYS Inc. (2018).

[56] M.A. Moghimi, K.J. Craig, J.P. Meyer, Optimization of a trapezoidal cavity absorber for the linear Fresnel reflector, Solar Energy 119 (2015) 343-361, doi:10.1016/j.solener.2015.07.009.

[57] M.A. Moghimi, K.J. Craig, J.P. Meyer, Simulation-based optimisation of a linear Fresnel collector mirror field and receiver for optical, thermal and economic performance, Solar Energy 153 (2017) 655-678, doi:10.1016/ j.solener.2017.06.001.

[58] M.A. Moghimi, G. Ahmadi, Wind barriers optimization for minimizing collector mirror soiling in a parabolic trough collector plant, Appl. Energy 225 (2018) 413-423, doi:10.1016/j.apenergy.2018.05.027. 
[59] M. Moghimi Ardekani, Optical thermal and economic optimisation of a linear Fresnel collector, Univer. Pretoria (2017).

[60] S. Seddegh, X. Wang, A.D. Henderson, A comparative study of thermal behaviour of a horizontal and vertical shell-and-tube energy storage using phase change materials, Elsevier Ltd (2016), doi:10.1016/ j.applthermaleng.2015.09.107.

[61] M. Esapour, M.J. Hosseini, A.A. Ranjbar, R. Bahrampoury, Numerical study on geometrical specifications and operational parameters of multi-tube heat storage systems, Appl. Therm. Eng. 109 (2016) 351-363, doi:10.1016/ J.APPLTHERMALENG.2016.08.083.

[62] M. Esapour, M.J. Hosseini, A.A. Ranjbar, Y. Pahamli, R. Bahrampoury, Phase change in multi-tube heat exchangers, Renew. Energy 85 (2016) 1017-1025, doi:10.1016/J.RENENE.2015.07.063.

[63] R.E. Murray, D. Groulx, Experimental study of the phase change and energy characteristics inside a cylindrical latent heat energy storage system: part $2 \mathrm{si}$ multaneous charging and discharging, Renew. Energy 63 (2014) 724-734, doi:10.1016/J.RENENE.2013.10.004. 